\title{
On a novel method for approximation of FN diagram and setting ALARP borders
}

\author{
Fujio Kaneko $\cdot$ Toshiro Arima $\cdot$ Koichi Yoshida • \\ Tomohiro Yuzui
}

Received: 1 December 2014 / Accepted: 12 January 2015/Published online: 3 February 2015

(C) The Author(s) 2015. This article is published with open access at Springerlink.com

\begin{abstract}
This article thoroughly reviews the state-ofthe-art methods for setting ALARP upper border as a straight line in logarithmic graph, which is the common practice in the risk assessments of nuclear, chemical plants and maritime facilities. It also reviews methods for setting ALARP upper border based on economic importance of a considered ship type. As a result, inconsistency related to ALARP upper border has been identified and new methods to resolve such inconsistency are developed. Here, firstly a method for approximating FN diagrams of existing major ship types is proposed and it is applied to ship types which consist of ships above 100 gross tonnage. After that the approximated FN diagrams were checked by goodness-of-fit test by $5 \%$ significance level, and it was validated that those approximated FN diagrams well express corresponding FN diagrams made from IHSF casualty and ship databases. This method can extrapolate FN diagrams made from those databases to the area of severer accidents with more fatalities, which have not been occurred yet, rationally. Secondly, problems that accompany with an existing method for setting ALARP upper border are discussed and methods for resolving the problems using the approximated FN diagrams are proposed. The methods can set ALARP upper border keeping consistency of ALARP upper border between individual risk and FN diagram. Lastly, the new method for safety analysis of ships using approximated FN diagrams of
\end{abstract}

F. Kaneko $(\bowtie) \cdot$ T. Arima $\cdot$ T. Yuzui

National Maritime Research Institute, Mitaka, Tokyo, Japan

e-mail: kaneko@nmri.go.jp

K. Yoshida

Centre for Oceanic Studies and Integrated Education (COSIE),

Yokohama National University, Yokohama, Japan major ship types is introduced. The method is used in order to find ships' groups which should be considered preferentially. The method for approximating FN diagrams and the method for setting ALARP upper border proposed here is so general that they can be applied to risk analysis of the fields which have a lot of accident records like maritime field, such as aviation or automotive fields.

Keywords FN diagram - Power law with maximum value $\cdot$ Approximation function $\cdot$ ALARP border

\section{Introduction}

Risk is an index to evaluate a safety level of a system under consideration. It is usually defined as a product of frequency and severity of consequences caused by an accident. Fatality risk, risk of sea pollution and property risk are major types of ship related risk. These types of risk are common to nuclear or chemical plants and aircraft, etc.

International Maritime Organization (IMO) developed "Revised Guidelines for Formal Safety Assessment (FSA) for Use in the IMO Rule-Making Process" [1] (hereinafter referred to as "FSA guidelines") in 2013. FSA guidelines show that there are "Individual risk" and "Societal risk" as expressions of fatality risk. "Individual risk" means an annual frequency that an individual person in or near a considered system is killed at an accident of the system. The unit of individual risk is [1/year], etc. This risk expression makes it possible to compare levels of safety between not only engineering systems, but also industries because this expression is widely used in many industries. As a nuclear or a chemical plant affects wide habited area around the plant at its accident, individual risk of the plant is different by location. Therefore, individual risk of such 
plant is usually expressed using contour lines. However, in a ship, except a ship like LNG tanker, whose cargo's explosion will affect surrounding habited area badly, it is considered to be reasonable to assume that individual risk of a ship is the same anywhere in the ship under consideration. Even though there exists difference of individual risk by location of a person onboard, here averaged individual risk is considered under the above assumption.

On the other hand, "societal risk" is a risk expression for a human group exposed to dangerous situation. Societal risk means a number of fatalities occurred in a human group during unit time length. A group of people onboard are regarded as one of such human groups. If "N" denotes the total number of fatalities occurred in all ships of a considered ship type during considered period and " $S$ " denotes a corresponding exposure of considered ship type, such as the sum of annual number of ships during considered period, PLL (Potential Loss of Lives) of the ship type is defined as N/S. PLL is a broadly used important risk expression. Unit of PLL is [persons/(ship $\times$ year)]. Another important expression of societal risk is FN diagram (frequency vs. number of fatalities diagram). FN diagram is a graph which shows exceedance frequency of number of fatalities.

Risk assessment has started gaining attention in the field of ships since FSA was introduced as a tool for rulemaking in the IMO. Several FSA proposals, such as FSA for bulk carrier safety [2, 3], FSA for mandating of IGS (Inert Gas System) [4] and FSA for mandating of ECDIS (Electronic Chart Display and Information System) [5], etc., were discussed during the first decade of this century. Also, in recent years, EU funded research project SAFEDOR (Design, Operation and Regulation for Safety) has carried out some FSAs to propose a number of RCOs (Risk Control Options) for enhancing safety of some ship types [6]. Risk assessment is an essential element of FSA procedures consisted of 5 steps. Furthermore, risk-based design was proposed by SAFEDOR [6]. Similar to FSA, risk assessment is also a main procedure in a risk-based ship design.

Making FN diagrams is an important procedure in risk assessment. Usually making FN diagrams is a time and labor consuming work which includes estimating occurrence frequency and consequences given in terms of number of fatalities, environmental pollution and property losses, of possible accident scenarios by examining them holistically. HSE (Health and Safety Executive) of UK [7, 8], proposed methods for shortening time and lightening load for making FN diagrams. The method called ARI $\mathrm{I}_{\mathrm{CO}}$ MAH that makes an FN diagram which ends at the point of the worst accident scenario whose coordinate is $\left(N_{\max }\right.$, frequency of the accident scenario whose number of fatality is $N_{\max }$ ) in double logarithmic graph, and the other part of an FN diagram is made by drawing a straight line which connects the point of the worst accident scenario and the point of a scenario whose number of fatalities is the possible minimum number with slope of -1 . In addition to this UKHSE proposed a one more method called Quick FN. In this method firstly a part of an FN diagram is made from $1 / 10$ of the maximum number of fatalities to the maximum number of fatalities by evaluating severe accident scenarios whose number of fatalities lies between such a domain after that a part of less than $1 / 10$ of $N_{\max }$ is made by drawing a straight line from the point at $1 / 10$ of $N_{\max }$ to the point at the minimum number of fatalities with slope of -1 .

On the other hand, unlike from chemical and nuclear plants, transportation facilities such as aircrafts, ships, cars and railways have so many fatal accident records that it can be easy to make FN diagrams of such facilities using accident records. In maritime field, however, when we consider a trend of construction of larger cruise ships, there is a possibility that accidents with more fatalities than before might happen. This means that making ship's FN diagram from only available accident records would make us fail to consider risk of such big accidents. To eliminate this possibility it is required to estimate the risk of big accidents by examining accident scenarios where more fatalities than before will be caused precisely in risk analysis. If it is possible to make an FN diagram beyond the maximum number of fatalities of past accidents with highly precise approximation of the FN diagram of past accidents by analyzing fatal accident records using rational method, it will be possible to get insight to risk by accidents with more fatalities than those of the past, before conducting time-consuming precise risk analysis.

In this regard, it is widely accepted to consider serious accidents such as fires and accidents of aircrafts, etc., to follow the power law and the CCDF (Complementary Cumulative Distribution Function) is power law distribution. In addition to them there are many phenomena which can be characterized by power law such as population of a city, number of citation of articles and number of accesses to Website, etc. Moreover, there are attempts to obtain parameters of power law distribution of some phenomena empirically $[9,10]$. An FN diagram can be obtained by multiplying frequency of fatal accidents and the corresponding CCDF. This means that an FN diagram and the corresponding CCDF is parallel on the plot.

However, there are fundamental drawbacks of the power law; the minimum value of random variable must be determined, and no upper limit of random variable is set. Therefore, it is not reasonable to introduce power law distribution as a CCDF of number of fatalities to maritime field where the minimum number of fatalities is one and the maximum number of fatalities cannot exceed the number of people onboard. Clauset et al. [9] tried to avoid 
the problem of minimum number by adding a part of CCDF of exponent distribution below the minimum number of $\mathrm{CCDF}$ of power law distribution. In addition, he tried to obtain parameters of power law distribution, which are an exponent and the minimum value of a random variable empirically. However, he did not attempt to deal with the maximum number of the random variable.

On the other hand, risk acceptance (or evaluation) criteria is one of important things in risk assessment. FSA guidelines explain those of individual risk and of societal risk. The common concept among most of fields is called "ALARP (as low as reasonably practicable)" principle. Following this concept risk are divided into three regions, which are intolerable region, ALARP region and negligible region. The meaning of these regions is briefly explained below.

The society can allow a considered system to work only when the risk locates in ALARP or negligible region. If the risk is in intolerable region it is required to immediately apply any risk control measures disregarding cost to reduce risk level to ALARP or to stop the system to work. If a risk of the system is in negligible region there is no need to apply any risk control measures. If the risk of the system is in ALARP region, if practicable, that is, if it is costeffective to apply certain risk control measures, they should be applied to the considered system, and so long as this procedure is continuously practiced, the society can allow the system to work.

To set ALARP upper border of individual risk at the level of $10^{-3}$ [1/year] is so widely adopted not only in maritime field, but also in other industrial fields that the criteria can be considered to be fully established. However, upper limit of individual risk cannot express the difference on consciousness of severity between an accident with 1000 fatalities and 1000 accidents with one fatality. It is so important to set ALARP upper border as it can express such difference in order to express the consciousness that the society refuses occurrence of the former more strictly than that of the latter. This consciousness is called risk aversion. Risk aversion can be also expressed by ALARP upper border of FN diagram. FSA guidelines suggest a method for setting ALARP upper border based on economic importance of considered ship group referring to MSC 72/16 [11]. The method for setting ALARP upper border has been de facto standard for a long time.

However, because there is a relation between individual risk and FN diagram, setting ALARP upper border of individual risk and that of FN diagram separately has a possibility that those two borders contradict each other. Moreover, to set ALARP upper border as a straight line on double logarithmic graph allows accidents with unlimited number of fatalities as power law distribution does. Such
ALARP upper border is said to be inappropriate for there is a limit to a number of fatalities caused in an accident of a ship. In addition, to set ALARP upper border as a straight line on double logarithmic graph has another drawback: allowance ratio between ALARP upper border and present FN diagram is smaller at more fatalities than that at less fatalities. As the above indication suggests there are some problems in the present ALARP upper border setting method. However, no literature which indicated these problems has not found so far.

In this article, two kinds of new methods are proposed after reviewing existing FN diagram and ALARP upper border setting methods holistically in order to enhance the effectiveness of risk assessment in FSA or risk-based design. One is a method for obtaining approximation function of CCDF made from casualty data of a ship group with high accuracy by newly developed function. The other is a method for setting ALARP upper border which can harmonize with that of individual risk and can fix abovementioned drawbacks of present ALARP upper border setting method. Moreover, those methods were verified by applying them to Information Handling Services Fairplay (IHSF) casualty and ship databases of the period from 1995 to 2011. Size of recorded ships in IHSF casualty and ship databases is equal and above 100 Gross Register Tonnage (GRT).

In the following sections, nine types of cargo carrying ships, i.e., LNG tanker, LPG tanker, chemical tanker, oil/ product tanker, bulk/ore carrier, general cargo ships, container ships, refrigerated cargo ships and RORO cargo ships, are considered. In addition, three types of passenger ships, i.e., passenger/general cargo ships, RORO passenger ships and passenger/cruise ships, are considered.

As ALARP lower borders can be obtained by sliding ALARP upper borders 2 or 3 digit down in double logarithmic graph, only ALARP upper borders are considered here using casualty data published by IHSF.

\section{A method for setting an approximation function of FN diagram}

\subsection{FN diagrams of major ship types}

Figure 1 shows FN diagrams of major ship types whose ships are of 100 GRT and above. Those diagrams are made using IHSF casualty and ship type databases during 17-year period from 1995 to 2011 . As there are only two records of fatal accidents in case of LNG tanker, it was decided that an FN diagram of LNG tanker is not considered hereafter.

FN diagrams are monotonically decreasing function with upward convex, although they are slightly bumpy. Those of container ship and of refrigerated carrier are 


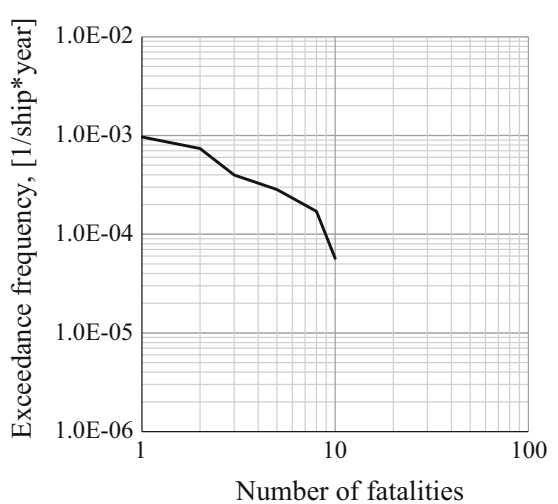

(a) LPG tanker

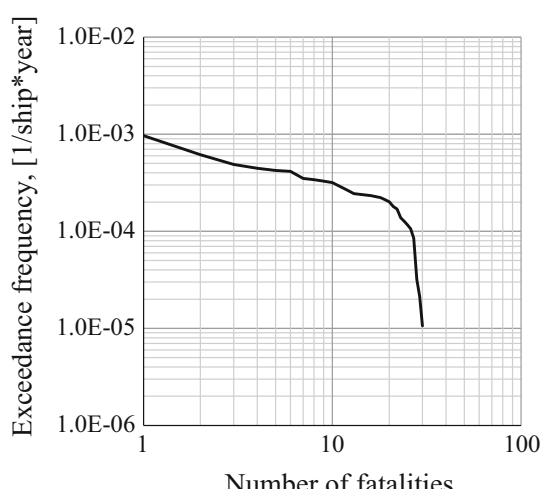

(d) Bulk/Ore carrier

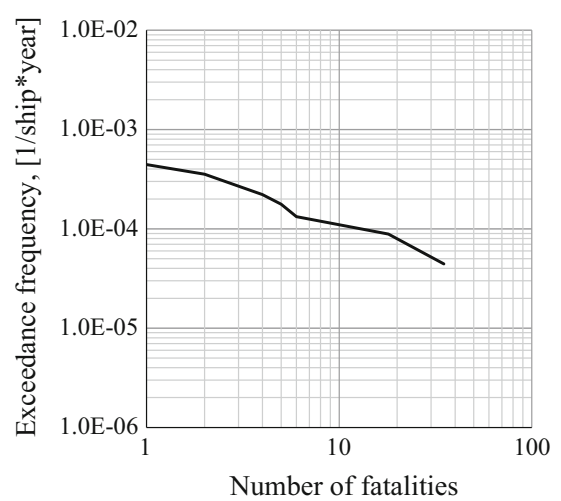

(g) Refrigerated cargo ship

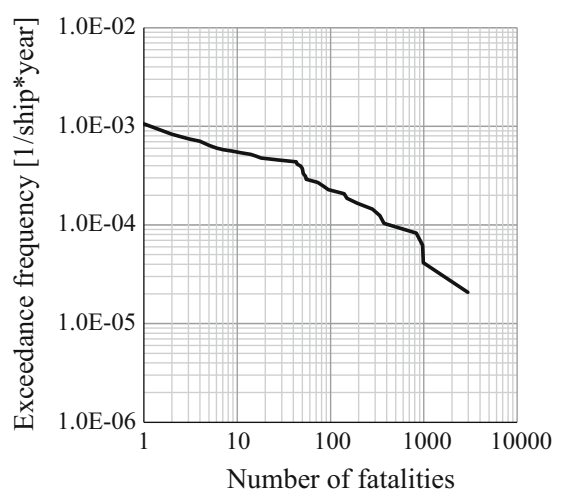

(j) RORO passenger ship

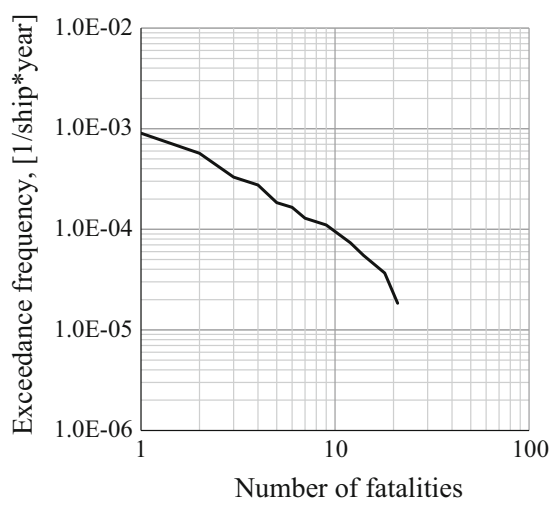

(b) Chemical tanker

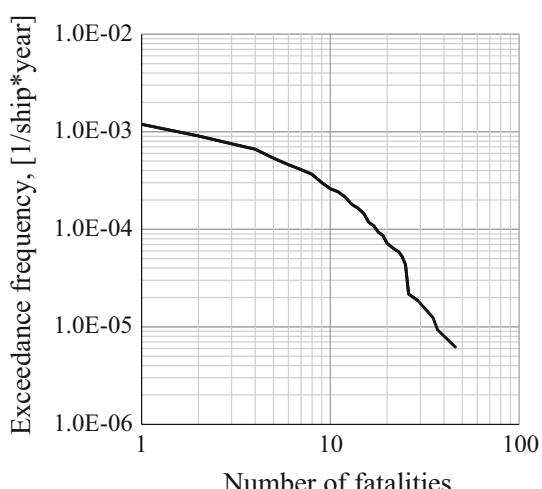

(e) General cargo ship

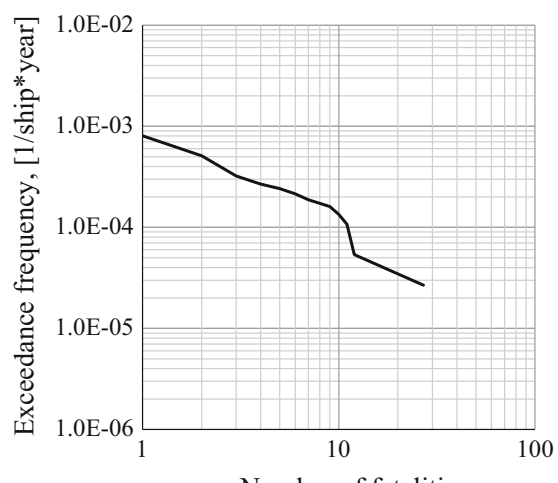

Number of fatalities

(h) RORO cargo ship

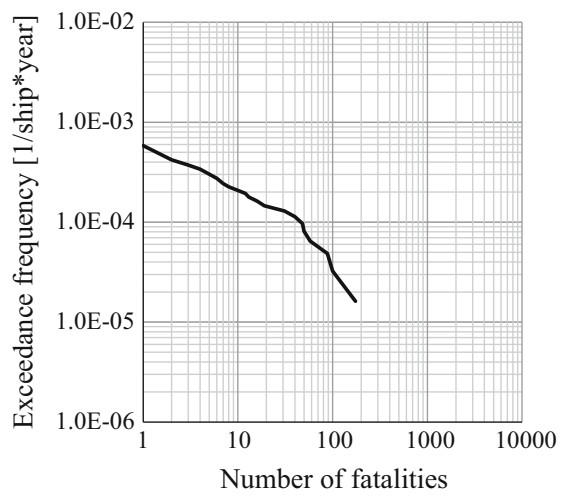

(k) Passenger/Cruise ship

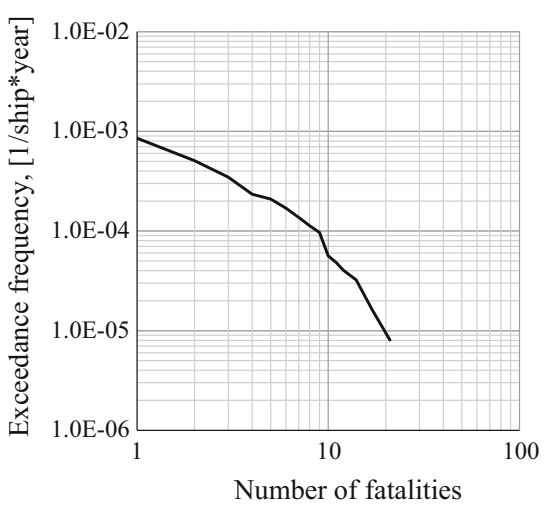

(c) Oil/Product tanker

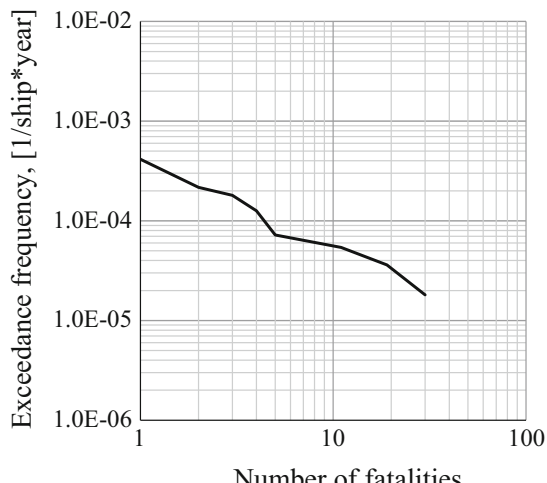

Number of fatalities

(f) Container ship

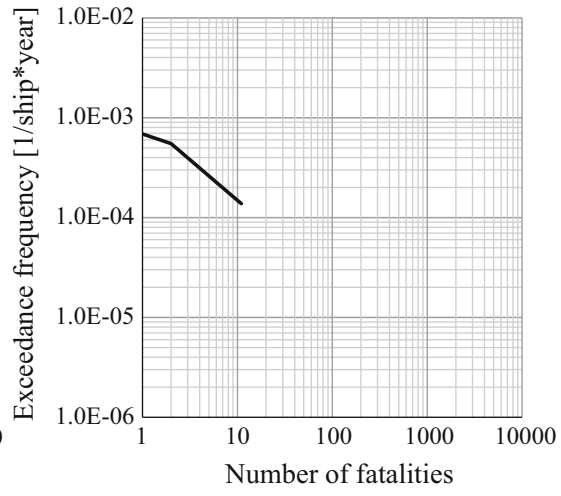

(i) Passenger/General cargo ship

Fig. 1 FN diagrams of major ship types of 100 GT and above 
mutually resembled and have downward corners at six or seven of the number of fatalities. FN diagrams of general cargo ships, of RORO cargo ships and of RORO passenger ships have downward corners at large number of fatalities. The FN diagram of bulk/ore carriers has a square shoulder at large number of fatalities. FN diagrams of bulk/ore carrier, RORO cargo ship and RORO passenger ship are downward convex a little at low number of fatalities. The least number of fatalities of every ship type is one.

As the number of fatal accidents increases, above observations might change. According to Table 7 it can be observed that there are some ship types, whose numbers of fatal accidents are dozens or over 100. Shapes of FN diagrams of such ship types are believed not to be changed greatly by adding fatal accidents after 2012 to the data which are used for making Fig. 1. What is important is that several characteristics of FN diagrams in Fig. 1 show fundamental problems arisen from the usage of straight lines in accordance with the current practice. Those problems can be solved by the approximation function introduced in the next section. It is important to use the approximation function which can approximate FN diagrams in Fig. 1 with high accuracy.

\subsection{Formulation by mixed discrete power law} distribution with upper limit (abbreviated form: MDPLDwUL)

Clauset et al. [9] define CCDF of discrete power law distribution as Eq. 1.

$\operatorname{CCDF}(n)=\frac{\varsigma(b, n)}{\varsigma\left(b, N_{\text {min }}\right)}$,

where CCDF ( $n$ ) denotes the value of CCDF at ' $n$ ' which denotes number of fatalities.

$\varsigma(b, n)$ is Hurwitz zeta function defined Eq. 2:

$\zeta(b, n)=\sum_{i=0}^{\infty}(i+n)^{-b}$,

where ' $b$ ' is positive value, ' $-b$ ' is an exponent of integers used in Eq. 2. In this article b with suffix such as 'bi' etc., is used as the ' $b$ ' in the definition of Hurwitz zeta function and the term 'exponent $(\mathrm{H})$ ' is also used to mention ' $b$ ' in the definition of Hurwitz zeta function for avoiding confusion.

$N_{\text {min }}$ in Eq. 1 denotes the least number of ' $n$ '. ' $n$ ' cannot take an number below $N_{\text {min }}$.

As Eq. 1, however, cannot deal with the upper limit of numbers of fatalities the equation is not suitable for CCDF of fatalities caused at ships' accidents. Here, Eq. 3 is formulated as the approximated CCDF which can deal with the upper limit of number of fatalities.

$$
\begin{aligned}
\operatorname{CCDF}_{\text {aprx }}(n) & =\frac{\sum_{i=n}^{N_{\max }} i^{-b}}{\sum_{i=N_{\min }}^{N_{\max }} i^{-b}} \\
& =\frac{\sum_{i=0}^{\infty}(i+n)^{-b}-\sum_{i=0}^{\infty}\left(i+N_{\max }+1\right)^{-b}}{\sum_{i=0}^{\infty}\left(i+N_{\min }\right)^{-b}-\sum_{i=0}^{\infty}\left(i+N_{\max }+1\right)^{-b}} \\
& =\frac{\zeta(b, n)-\zeta\left(b, N_{\max }+1\right)}{\zeta\left(b, N_{\min }\right)-\zeta\left(b, N_{\max }+1\right)},
\end{aligned}
$$

where $\mathrm{CCDF}_{\text {aprx }}(n)$ denotes value of approximated CCDF where number of fatalities is $n, N_{\max }$ denotes maximum number of fatalities. We call the CCDF described by Eq. 3 Discrete Power Law Distribution with Upper Limit (abbreviated form: DPLDwUL).

In addition, it should be considered that ships of the same ship type differ in their number of people onboard. We can estimate a number of accidents whose number of fatalities is ' $n$ ' from the corresponding number of accidents of all sub-groups of a ship type using every sub-group's number of accidents and its $\mathrm{CCDF}(\mathrm{CCDFi}(n))$ described by DPLDwUL of Eq. 3.

Here suppose that $N_{\text {FAT-ALL }}(\mathrm{n})$ denotes all sub-groups' number of fatal accidents where the number of fatalities is $\mathrm{n}$ and the above, Eq. 4 holds.

$N_{\mathrm{FAT}-\mathrm{ALL}}(n)=\sum_{i=1}^{M} N_{\mathrm{FAT}-i}(n)=\sum_{i=1}^{M} N_{\mathrm{FAT}-i}(1) \cdot C C D F_{i}(n)$

where $n$ denotes the number of fatalities, $N_{\text {FAT-i }}(n)$ denotes the number of fatal accidents of sub-group $i$ whose number of fatalities is $n$ and above. $M$ denotes the number of sub-groups.

Then the CCDF of all sub-groups is obtained by Eq. 5 .

$$
\begin{aligned}
\operatorname{CCDF}_{\text {aprx }-\mathrm{ALL}}(n) & =\frac{N_{\mathrm{FAT}-\mathrm{ALL}}(n)}{N_{F A T-A L L}(1)} \\
& =\frac{\sum_{i=1}^{M} N_{\mathrm{FAT}-i}(1) \cdot C C D F_{\mathrm{aprx}-i}(n)}{\sum_{i=1}^{M} N_{\mathrm{FAT}-i}(1)} \\
& =\sum_{i=1}^{M} \frac{N_{\mathrm{FAT}-i}(1)}{\sum_{i=1}^{M} N_{\mathrm{FAT}-i}(1)} \cdot \mathrm{CCDF}_{\mathrm{aprx}-i}(n)
\end{aligned}
$$

Equation 5 can be rewritten by Eq. 6

$$
\begin{aligned}
\operatorname{CCDF}_{\text {aprx-ALL }}(n) & =\sum_{i=1}^{M} r_{i} \cdot \operatorname{CCDF}_{\text {aprx-i }}(n) \\
& =\sum_{i=1}^{M} r_{i} \cdot \frac{\zeta\left(b_{i}, n\right)-\zeta\left(b_{i}, N_{\max -\mathrm{i}}+1\right)}{\zeta\left(b_{i}, N_{\min -\mathrm{i}}\right)-\zeta\left(b_{i}, N_{\max -\mathrm{i}}+1\right)}
\end{aligned}
$$


where $r_{i}$ is defined below.

$r_{i}=\frac{N_{\mathrm{FAT}-i}(1)}{\sum_{i=1}^{M} N_{\mathrm{FAT}-i}(1)}\left(\sum_{i=1}^{M} r_{i}=1\right)$.

Then, paying attention to the fact that there is a maximum number of fatalities to every sub-group, Eq. 8 holds.

$\operatorname{CCDF}_{\text {aprx }-i}(n)=0 \quad n>N_{\text {max }-\mathrm{i}}$

where $N_{\text {max-i }}$ denotes the maximum number of fatalities of sub-group $i$, and it is assumed that $N_{\max -1} \leq N_{\max -2}$ $\leq \cdots N_{\max -\mathrm{M}}$.

Equation 6 suggests that CCDF for all sub-groups, that is, for ships belonging to a ship type, is given by a linear combination of CCDFs fitted to every sub-group. A linear combination of some elemental probabilistic distributions is called mixed distribution. We call the probabilistic distribution whose CCDF is given by Eq. 6 Mixed Discrete Power Law Distribution with Upper Limit (abbreviated form: MDPLDwUL).

\subsection{Expressive capability of MDPLDwUL}

The important thing is whether MDPLDwUL can approximate CCDF of every major ship type which is obtained by dividing FN diagram of every major ship type by number of fatal accidents [FN(1)] or not. In this section an example is considered for examining expressive capability of MDPLDwUL.

Figure 2 shows MDPLDwUL where $M=3, b_{1}=5.0$, $b_{2}=0.5, \quad b_{3}=0.7, \quad r_{1}=0.5, \quad r_{2}=0.2, \quad r_{3}=0.3$, $N_{\max -1}=10, N_{\max -2}=100$ and $N_{\max -3}=1000$ as a double logarithmic graph. The curve in Fig. 2 expresses downward convex around 5 and a corner at 100. This means that MDPLDwUL can express features of FN diagrams of major ship types.

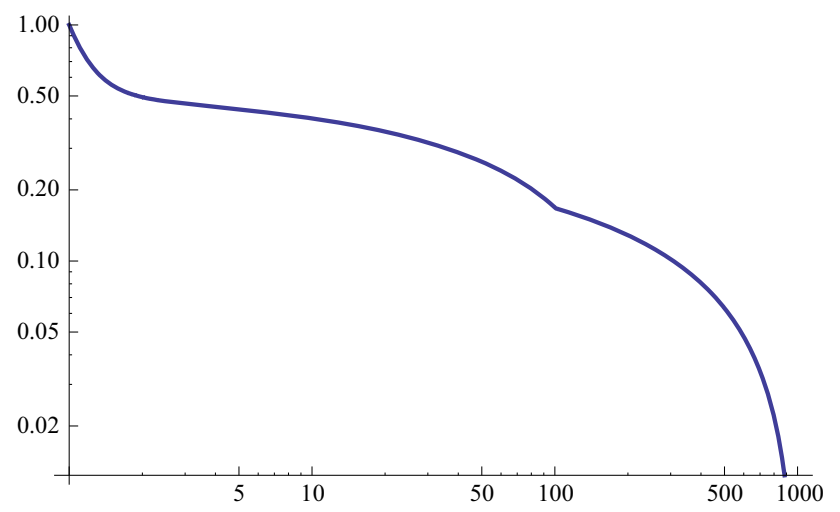

Fig. 2 An example of MDPLDwUL (Mixed Discrete Power Law Distribution with Upper Limit)
The next section shows a method for obtaining parameters of MDPLDwUL from an empirical FN diagram made using casualty data.

2.4 A method for obtaining parameters of MDPLDwUL from an empirical FN diagram made using casualty data

Clauset et al. [9, 10], proposed a method for obtaining parameters by maximum likelihood estimation method (MLE) from probabilistic distribution function or complementary cumulative distribution function empirically made based on observed values. The parameters included the minimum number and exponent of a random variable denoted, respectively, as $N_{\min }$ and $b$ in Eq. 1 . What is necessary, however, is to obtain parameters of the mixed distribution including the maximum number and exponent $(\mathrm{H})$ for the number of fatalities, and the ratio of every subgroup. Moreover, there is no prior knowledge on the subgroups. Therefore, another method should be investigated. Train [12] proposed a method that after formulation by MLE Expectation-maximization (EM) algorithm is employed for solving it, as a method for estimation of mixed distribution. Here, we propose a method to estimate the parameters of Eq. 6 which minimize the total sum of square of deviation between empirical CCDF and theoretical approximation function. This method uses a formulation by least square method (LSM).

In this case, there are two ways for the formulation. One is to use absolute difference between empirical and theoretical $\mathrm{CCDF}$, and the other is to use a difference between logarithms of those values in optimizing calculation to obtain optimal parameters.

Under formulation by absolute difference of both CCDFs, difference of the CCDFs at small number of fatalities and that at large number of fatalities have the same magnitude. Therefore, the latter difference becomes larger than the former difference comparatively by optimization in double logarithmic graph. Contrary to this, formulation by difference between logarithmic values of the CCDFs even if same absolute difference of the CCDFs evaluate a difference at large number of fatalities heavier than that at small number of fatalities. For risk assessment evaluates accidents with large number of fatalities much heavier than those with small number of fatalities, it can be concluded that using difference between logarithmic value of CCDFs is suitable. Therefore, we adopted the difference between logarithmic values of CCDFs in the formulation when obtaining parameters of all ship types' approximation functions of FN diagrams by MDPLDwUL. We also tried to formulate by MLE to obtain the parameter of general cargo ships. However, the total sum of differences between the CCDFs of MLE was larger than that by the formulation 
by LSM in the ship type. As we can see at a later section, it is confirmed that an approximation function of every ship type obtained by this method is highly precise to the extent that it can pass the goodness-of-fit test.

Taking an example of general cargo ship, we shortly indicate that the more number of sub-groups the closer an approximated CCDF by MDPLDwUL gets to an empirical CCDF at Fig. 3 and Table 1. Table 1 also contains values of parameters. Figure 3 shows that the upward-convex part at the comparative small number of fatalities, which is called "bulge" in the article [7], and a corner at large number of fatalities in empirical CCDF are more closely fitted by the approximate CCDF for the larger number of sub-groups. Corresponding to this, Table 1 shows that the total sum of square of deviation between logarithmic $\mathrm{CCDFs}$ becomes smaller as number of sub-groups gets more. However, the total sum of four sub-groups is not so much improved than that of three sub-groups. The same is observed in Fig. 3c, d. It can be said that limitation of the number of sub-groups exists from fitting goodness's point of view. Therefore, the number of sub-groups of every ship type was determined considering limitation of fitting goodness.
Variables to be obtained are $b_{i}, r_{i}\left(r_{M}=1-\sum_{j=1}^{M-1} r_{j}\right)$, $N_{\text {max }-i},(i=1, \ldots, M)$ in Eq. 6. Objective function to be minimized is ' $F$ ' defined by Eq. 9 .

For the minimization of " $F$ " we employed DavidonFletcher-Powell method which is one of conjugate gradient methods. The outline of the method is explained briefly in the Appendix.

$$
\begin{aligned}
F= & \sum_{j=1}^{N_{\text {data }}}\left(\operatorname{Ln}\left(\mathrm{CCDF}_{\text {aprx }-\mathrm{ALL}}(k(j))\right)\right. \\
& \left.-\operatorname{Ln}\left(\mathrm{CCDF}_{\text {data-ALL }}(k(j))\right)\right)^{2} \\
= & \sum_{j=1}^{N_{\text {data }}}\left(\operatorname{Ln}\left(\sum_{i=1}^{M} r_{i} \cdot \mathrm{CCDF}_{\text {aprx }-\mathrm{i}}(k(j))\right)\right. \\
& \left.-\operatorname{Ln}\left(\mathrm{CCDF}_{\text {data }-\mathrm{ALL}}(k(j))\right)\right)^{2}
\end{aligned}
$$

where $k(j)$ denotes $j$ th number of fatalities which are recorded in IHSF casualty database, $N_{\text {data }}$ denotes total number of recorded number of fatalities in IHSF casualty database and $\operatorname{Ln}(x)$ denotes the natural logarithm of $x$.

In addition $N_{\max -i},(i=1, \ldots, M)$ is a natural number so that it is difficult to deal with $N_{\text {max }-i}$ by Davidon-Fletcher-
Fig. 3 Improvement of fitting CCDF made from casualty data by MDPLDwUL as increasing number of sub-groups. (Ship type: General cargo ship)

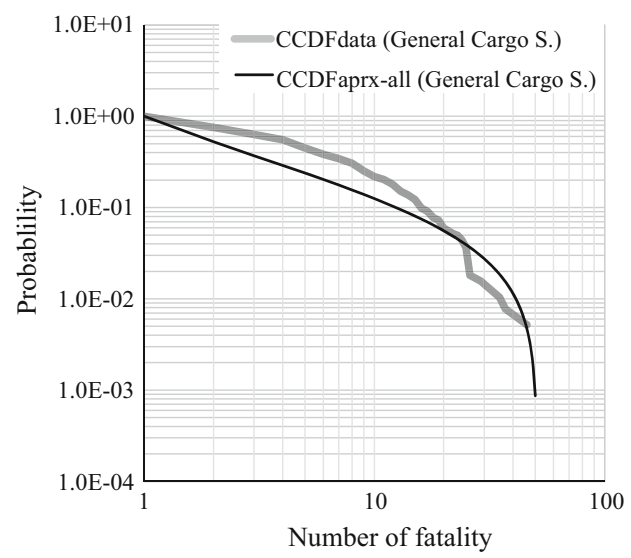

(a) Number of sub-groups : 1

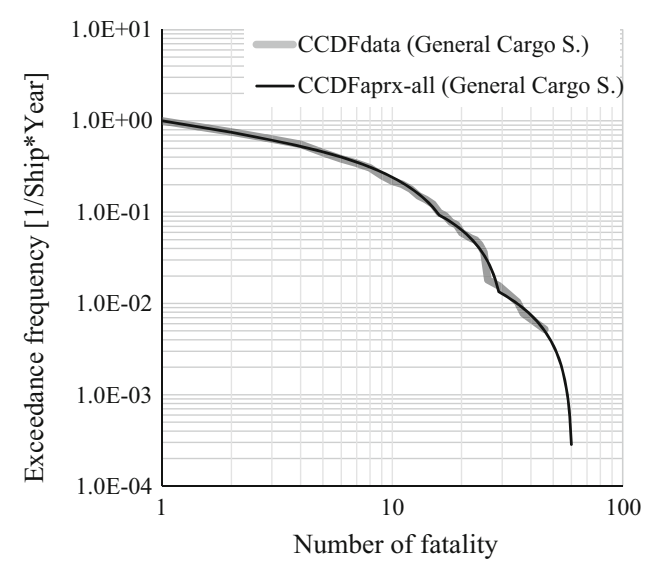

(c) Number of sub-groups : 3

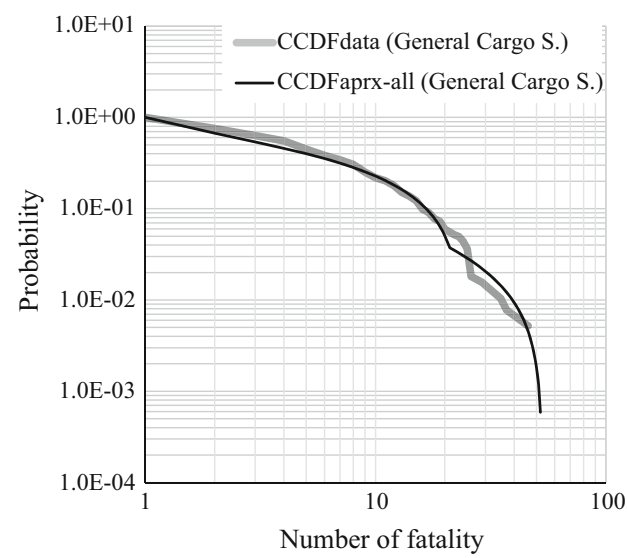

(b) Number of sub-groups : 2

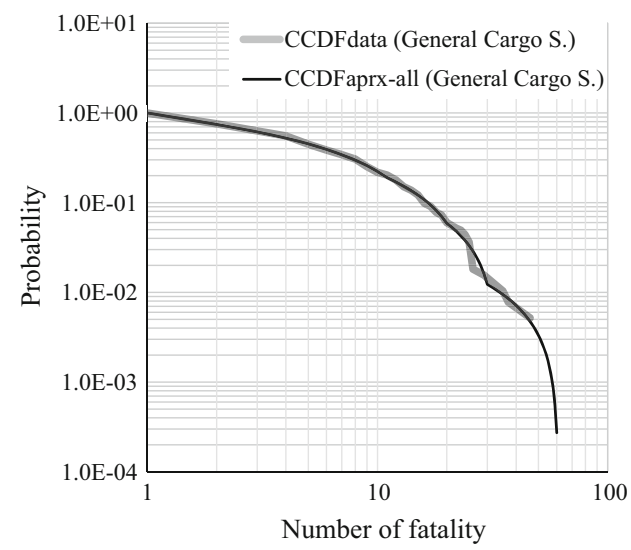

(d) Number of sub-groups : 4 


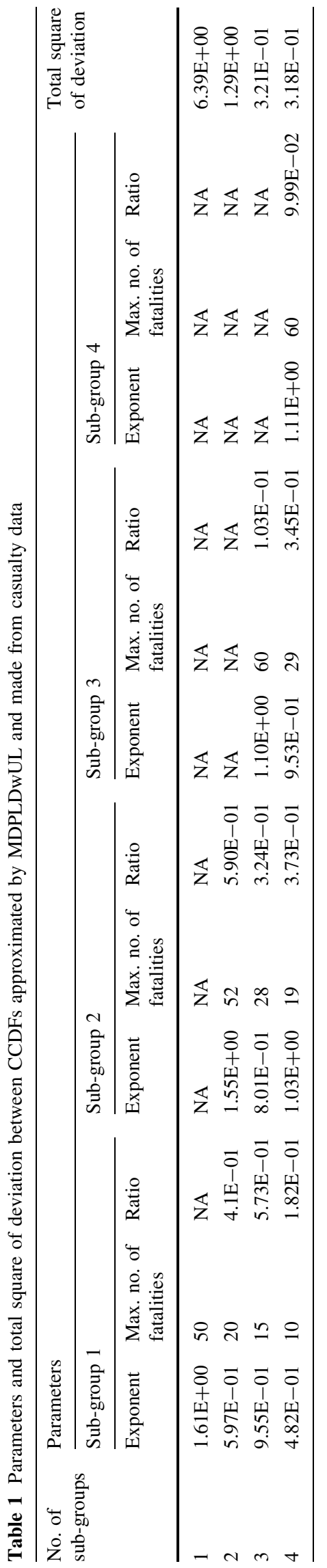

Powell method which is used to obtain continuous values. Therefore, when $b_{i}$ and $r_{i}$ are almost converged after a certain number of iterating minimizing calculation $N_{\text {max-i }}$ is changed from the smallest to minimize " $F$ ". All parameters of MDPLDwUL can be obtained by iterating these calculations till ' $F$ ' gets to the minimum value.

\subsection{Approximation functions of FN diagrams of major ship types by MDPLDwUL}

Figure 4 shows approximated FN diagrams of major ship types with FN diagrams made from casualty data. Approximated FN diagram of every ship type is made by multiplying approximated CCDF by frequency of fatal accidents [FN (1)] of the ship type. As there are very few fatal accidents in case of passenger/general cargo ship during considered period, this ship type is omitted. In relation to this in Fig. 4 symbol $i$ which is used in Fig. 1 for passenger/general cargo ship is not used for keeping correspondence with Fig. 1. Table 2 shows every ship type's parameters of MDPLDwUL.

Figure 4 shows good fitness of approximation function to FN diagram made from IHSF casualty and ship databases including corners and bulges. In addition the approximation functions can express FN diagram over the maximum number of fatalities of real accidents. This method is not biased because an approximation function can be obtained by being formulated as optimization problem without arbitral setting.

Table 2 shows that ship types whose sub-groups' exponent $(\mathrm{H}) \mathrm{s}$ are all over 1.0 are only chemical tanker and oil/ product tanker. We may observe that exponent $(\mathrm{H}) \mathrm{s}$ of all sub-groups in a ship type are over 1.0, which means the ship type shows risk aversion, as is explained in the next chapter.

\section{Problems that accompany the conventional methods to set ALARP upper borders on FN diagrams and a consideration of risk aversion}

In this chapter, firstly a direct method for expressing risk aversion is explained after discussing these problems that accompany the conventional methods to set ALARP upper borders.

\subsection{A method for expressing risk aversion by ALARP upper border}

Risk aversion is one of important concepts at setting ALARP upper border. Risk aversion reflects a society's view that one accident with 1000 fatalities is less acceptable than 1000 accidents with 1 fatality. Risk aversion is usually expressed by ALARP upper borders on FN diagrams. 
Fig. 4 Approximated FN diagram of every major ship type by MDPLDwUL

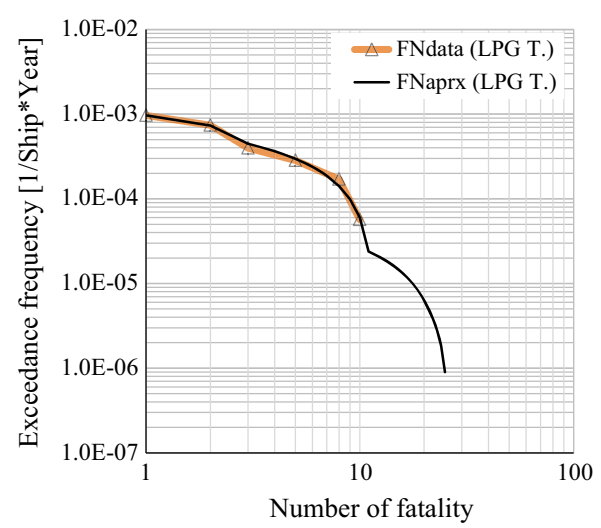

(a) LPG tanker

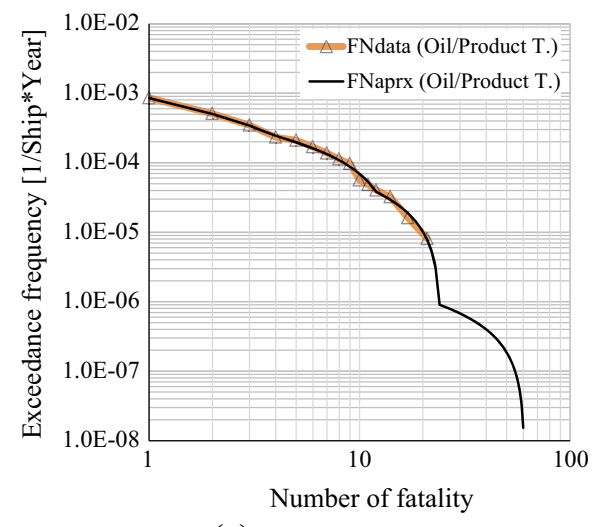

(c) Oil/Product tanker

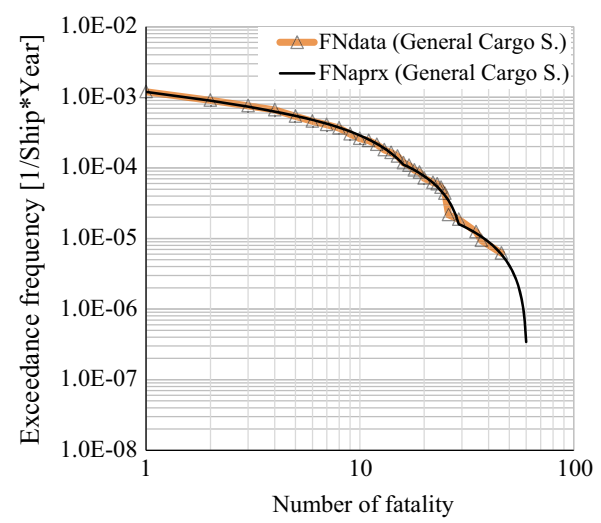

(e) General cargo ship

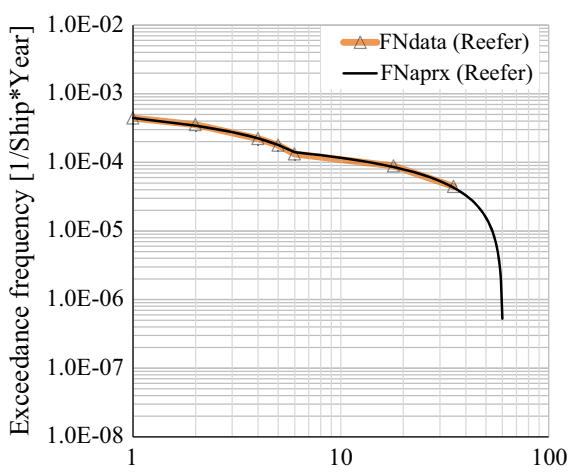

(g) Number of fatality

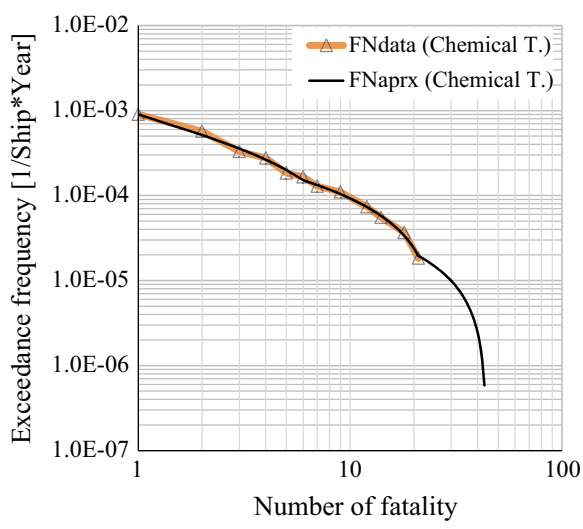

(b) Chemical tanker

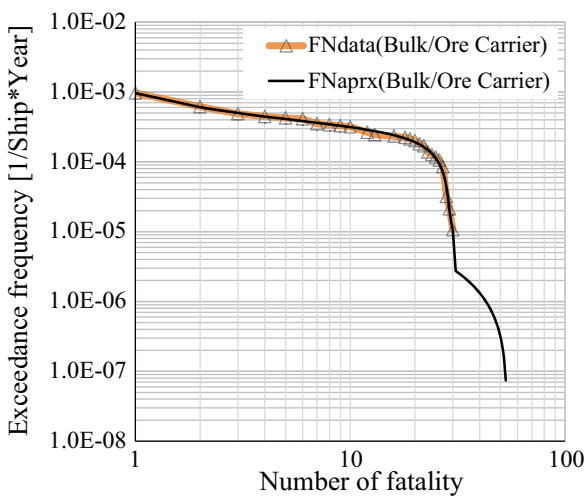

(d) Bulk/Ore carrier

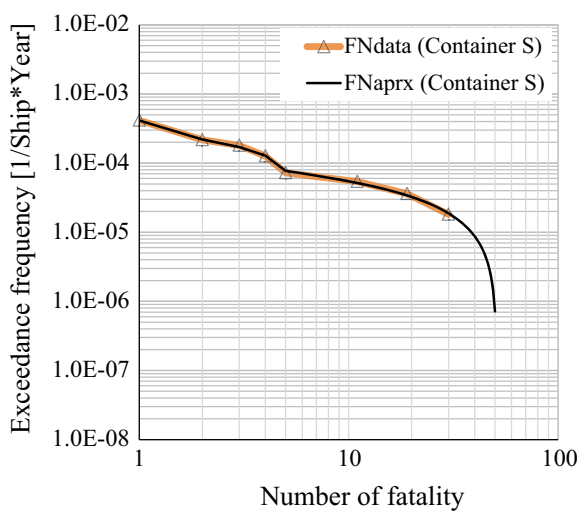

(f) Container ship

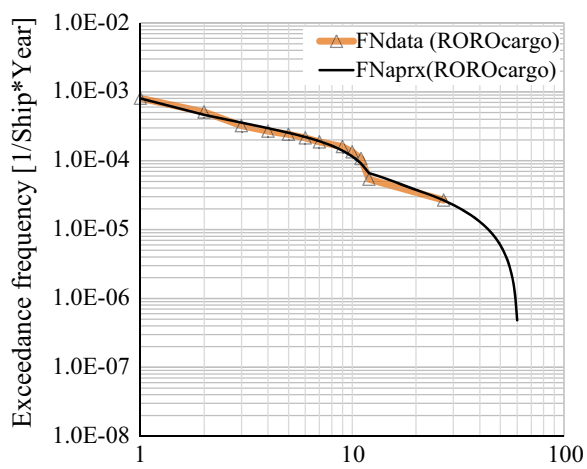

(h) Number of fatality 
Fig. 4 continued

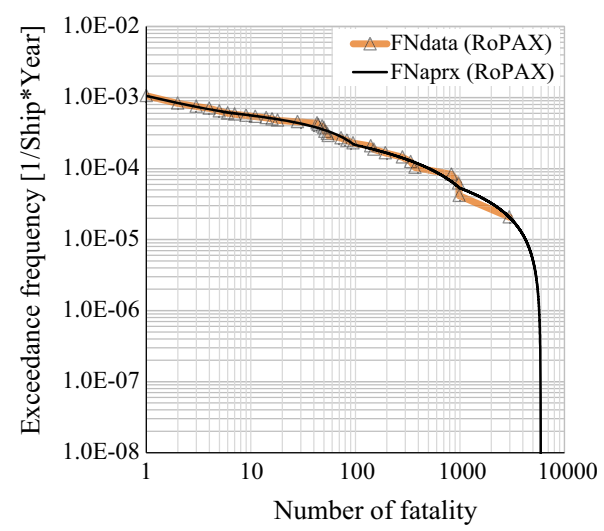

(i) RORO passenger ship



(j) Passenger/Cruise ship
Jonkman et al. [13] and Vrijling et al. [14] call the setting slope of an ALARP upper border to be -2 in double logarithmic graph risk averse and call the setting the slope to be -1 risk neutral. On the other hand, MSC 72/16 shows the view that the setting the slope of ALARP upper border to be -1 is risk averse.

In this section, we define risk aversion as a principle that for a given ship type, a contribution of accidents with more fatalities to PLL is smaller than that with less fatalities. This principle is followed to the view expressed in MSC 72/16 [11]. This definition is called "Principle A" here. We try to set ALARP upper border to fulfill Principle A strictly.

Following Principle A the inequality in Eq. 10 can be hold.

$f n\left(n_{1}\right) \cdot n_{1} \leq f n\left(n_{2}\right) \cdot n_{2}\left(n_{1} \geq n_{2}\right)$

where $n_{1}$ and $n_{2}$ denote number of fatalities.

It should be noted that fn $(n)$ is not an exceedance frequency of accidents where the number of fatalities is $n$ and above, but the frequency of accidents where number of fatalities is just $n$. The value obtained as $\mathrm{fn}(n)$ divided by frequency of all fatal accidents, that is, $\mathrm{fn}(n) / \mathrm{FN}(1)$ is a probability as the sum of $\mathrm{fn}(n) / \mathrm{FN}(1)$ from the minimum number of fatalities to the maximum makes 1 . As the number of fatalities is a discrete number, probabilistic density function (PDF) of the same meaning with that of continuous random value does not exist. However, as it is possible to call $\frac{f n(n)}{F N(1)}$ PDF. we call $\frac{f n(n)}{F N(1)}$ PDF and use a symbol PDF $(n)$ for $\frac{f n(n)}{F N(1)}$.

Now, we consider a condition where DPLDwUL defined as Eq. 3 satisfy Principle A.

PDF $(n)$ of DPLDwUL can be expressed as Eq. 11.

$$
P D F(n)=\frac{n^{-b}}{\sum_{i=N_{\min }}^{N_{\max }} i^{-b}}
$$

From Eq. 10, the next inequality must hold.
$\operatorname{PDF}\left(n_{1}\right) \cdot n_{1} \leq \operatorname{PDF}\left(n_{2}\right) \cdot n_{2}$

From Eq. 11 and the inequality in Eq. 12 next inequality is derived.

$\frac{n_{1}^{-b} \cdot n_{1}}{\sum_{i=N_{\min }}^{N_{\max }} i^{-b}} \leq \frac{n_{2}^{-b} \cdot n_{2}}{\sum_{i=N_{\min }}^{N_{\max }} i^{-b}}$

From the inequality in Eq. 13 the inequality in Eq. 14 is derived.

$n_{1}^{-b+1} \leq n_{2}^{-b+1}$

For the inequality in Eq. 14 holds $-b+1$ must be negative. Or $b$ must be over 1 .

If all elemental DPLDwULs' exponent(H)s are over 1.0, it is self-evident that MDPLDwUL, which is linear combination of elemental DPLDwULs, must satisfy Principle A. Therefore, if all sub-groups' DPLDwULs' exponent $(\mathrm{H}) \mathrm{s}$ are over 1.0, the line which is parallel to the FN diagram that is obtained by multiplying CCDF approximated by the MDPLDwUL by FN(1), satisfies Principle A. This means that if such line is used as ALARP upper border, the border satisfies Principle A. However, if some of elemental DPLDwULs have exponent $(\mathrm{H}) \mathrm{s}$ of below 1.0, it is not sure that all points of the ALARP border satisfy Principle A.

Figure 5 shows ALARP upper borders set by several countries. These lines are all straight in double logarithmic graph. The UK's line passes through $\left(1,10^{-2}\right)$ with slope 1. The Denmark's line passes through the same point at the left end, with slope -2 . The Hong Kong's line passes through $\left(1,10^{-3}\right)$ with slope -1 . The line, however, does not allow an accident whose number of fatalities is over 1000. The Netherlands' line passes through the same point at the left end as Hong Kong's line, with slope -2 .

FSA guidelines include Table 3 which shows ALARP border of individual risk of some human categories. The guidelines also include a description on ALARP upper borders which are set based on economic importance 


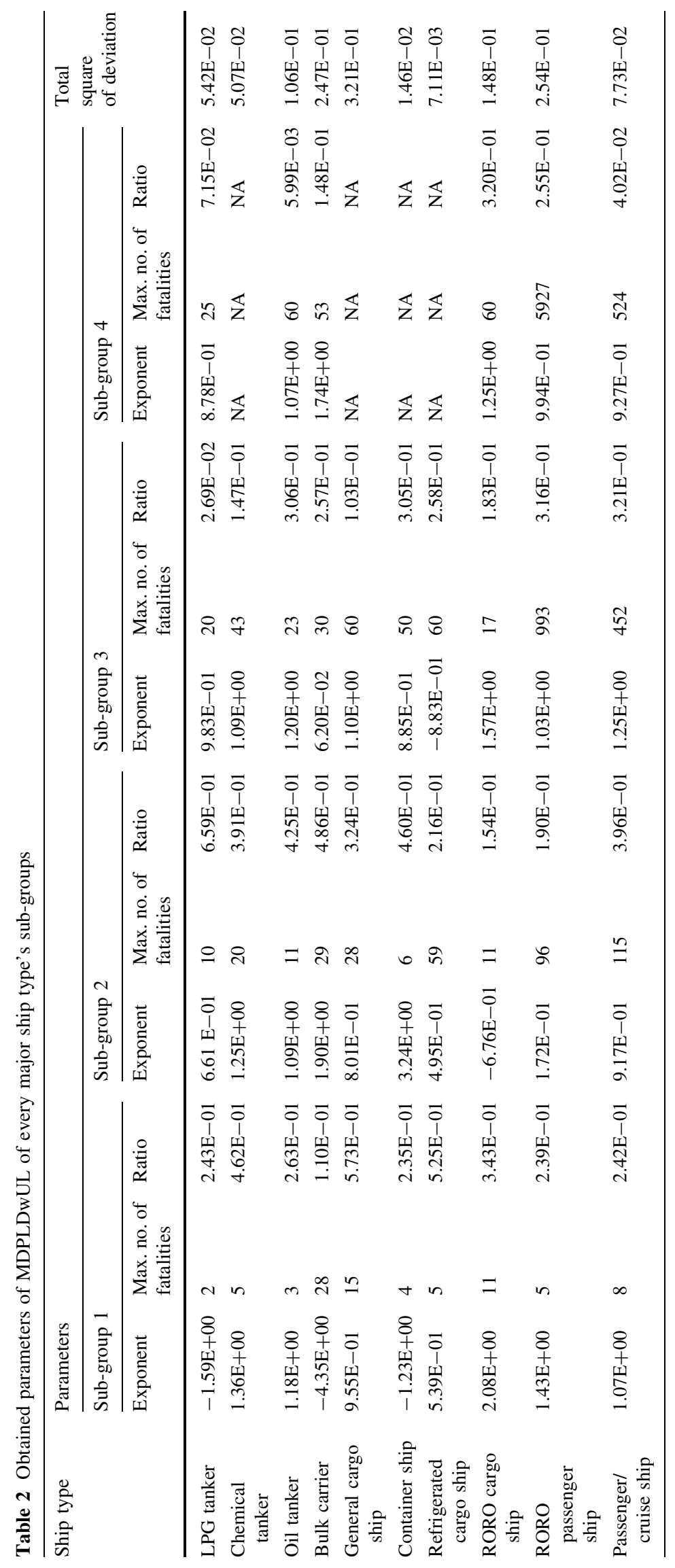




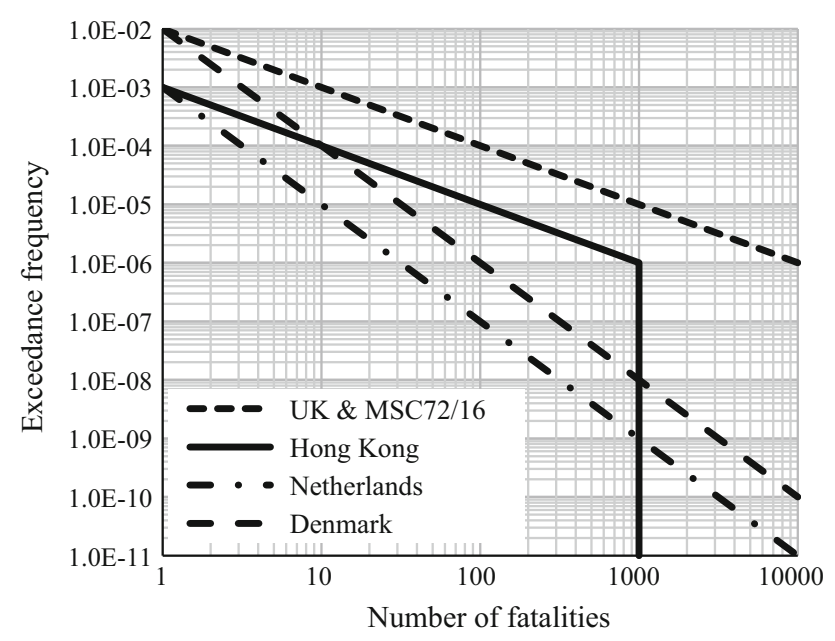

Fig. 5 ALARP upper border used in several countries

measured by annual income. They are set irrespective of ALARP upper border of individual risk. As we see in the followings it should be noted that there exists discrepancy between these two ALARP upper borders.

\subsection{Discrepancy between ALARP upper border of individual risk and that of FN diagram}

As mentioned above, FSA guidelines include a description on how to set ALARP upper border to FN diagrams, referring to corresponding description of MSC 72/16 [11] which indicates that a ship which gain more income can allow more fatalities than a ship which gain less income. There exists discrepancy between ALARP upper border of individual risk and that of FN diagram. In this section, the discrepancy is explained precisely using relation between them.

\subsubsection{Relation between PLL and FN diagram}

PLL is a sum of values of the vertical coordinates along whole FN diagram which represents exceedance frequencies. This is shown by following development of equations.

PLL is defined as Eq. 15

$\mathrm{PLL}=\sum_{i=N_{\min }}^{N_{\max }} i \cdot f n(i)$

Equation (14) is transformed as followings.

$$
\begin{aligned}
\mathrm{PLL} & =\sum_{i=N_{\min }}^{N_{\max }} i \cdot f n(i) \\
= & \sum_{i=N_{\min }}^{N_{\max }-1} i \cdot(F N(i)-F N(i+1))+N_{\max } \cdot F N\left(N_{\max }\right) \\
& \times\left(\because F N\left(N_{\max }\right)=f n\left(N_{\max }\right)\right)
\end{aligned}
$$

$$
\begin{aligned}
= & \sum_{i=N_{\min }}^{N_{\max }-1} i \cdot F N(i)-\sum_{i=N_{\min }}^{N_{\max }-1} i \cdot F N(i+1)+N_{\max } \cdot F N\left(N_{\max }\right) \\
= & \sum_{i=N_{\min }}^{N_{\max }-1} i \cdot F N(i)-\sum_{i=N_{\min }}^{N_{\max }-1}(i+1) \cdot F N(i+1) \\
& +\sum_{i=N_{\min }}^{N_{\max }-1} F N(i+1)+N_{\max } \cdot F N\left(N_{\max }\right) \\
= & \sum_{i=N_{\min }}^{N_{\max }-1} i \cdot F N(i)-\sum_{i=N_{\min }+1}^{N_{\max }} i \cdot F N(i)+\sum_{i=N_{\min }}^{N_{\max }-1} F N(i+1) \\
& +N_{\max } \cdot F N\left(N_{\max }\right)=N_{\min } \cdot F N\left(N_{\min }\right)-N_{\max } \cdot F N\left(N_{\max }\right) \\
& +\sum_{i=N_{\min }+1}^{N_{\max }} F N(i)+N_{\max } \cdot F N\left(N_{\max }\right) \\
= & N_{\min } \cdot F N\left(N_{\min }\right)+\sum_{i=N_{\min }+1}^{N_{\max }} F N(i)
\end{aligned}
$$

When $N_{\text {min }}=1$ Eq. 16 holds.

$\mathrm{PLL}=1 \cdot F N(1)+\sum_{i=1+1}^{N_{\max }} F N(i)=\sum_{i=1}^{N_{\max }} F N(i)$

As ALARP upper border is the upper limit of FN diagram, its PLL is given by a sum of values of vertical coordinates along whole ALARP upper border.

Therefore PLL of ALARP upper border can be expressed as Eq. 17 when $N_{\min }=1$.

$\operatorname{PLL}_{\text {ALARP-U }}=\sum_{i=1}^{N_{\max }} \operatorname{FN}_{\text {ALARP-U }}(i)$,

where $\mathrm{FN}_{\text {ALARP-U }}(n)$ denotes approximation function of ALARP upper border of FN diagram and PLL ALARP-U denotes PLL of FN ALARP-U $_{\text {U }}(n)$.

\subsubsection{Relation between individual risk and PLL}

The individual risk for a person will differ depending on the environment within which the person lives. However, in case that there is a clear border to the space where a person exists and every person's moving range is thought to be almost the same like a ship, it is rational that risk to every person is same. Therefore, individual risk of a ship is obtained by dividing PLL by the number of persons onboard. In the same way individual risk of a ship type can be obtained by dividing PLL of the ship type by the average number of people onboard. The value can be obtained by Eq. 18:

IR $=\frac{\text { PLL }}{N_{\text {obd }}}$, 
Table 3 Quantitative risk evaluation upper and lower bounds [1]

\begin{tabular}{llll}
\hline Decision parameter & Acceptance criteria & \\
\cline { 3 - 4 } & & $\begin{array}{l}\text { Lower bound for ALARP region } \\
\text { Negligible (broadly acceptable) fatality } \\
\text { risk per year }\end{array}$ & $\begin{array}{l}\text { Upper bound for ALARP region } \\
\text { Maximum tolerable fatality risk per year }\end{array}$ \\
\hline Individual risk & To crew member & $10^{-6}$ & $10^{-3}$ \\
& To passenger & $10^{-6}$ & $10^{-4}$ \\
& To third parties member of public ashore & $10^{-6}$ & $10^{-4}$ \\
& Target values for new ships & $10^{-6}$ & Above values to be reduced \\
Societal risk one order of magnitude
\end{tabular}

where IR denotes individual risk and $N_{\text {obd }}$ denotes average numbers of people onboard.

Here for the simplification it is assumed that numbers of people onboard of a ship of a considered ship type has been the same during specified period.

Equation 17 indicates that ALARP upper value of PLL can be given by a sum of values of vertical coordinates along whole ALARP upper border. Therefore, from Eqs. 17 and 18, Eq. 19 can be derived.

$$
\begin{aligned}
\mathrm{IR}_{\mathrm{ALARP}-\mathrm{U}} \cdot N_{\mathrm{obd}} & =\mathrm{PLL}_{\mathrm{ALARP}-\mathrm{U}}=\sum_{i=1}^{N_{\max }} \mathrm{FN}_{\mathrm{ALARP}-\mathrm{U}}(i) \\
& =\sum_{i=1}^{N_{\max }} i \cdot \mathrm{fn}_{\mathrm{ALARP}-\mathrm{U}}(i)
\end{aligned}
$$

Equation 19 indicates that summation of ALARP upper border equals to the value of multiplication of ALARP upper values and average numbers of person onboard. This means that summation of ALARP upper border $\left(\mathrm{PLL}_{\mathrm{A}}\right.$ LARP-U) set by the method in MSC 72/16 [11], that is ALARP upper border on FN diagram of a ship, should be determined in association with her economic importance is different from the value of multiplication of ALARP upper values and average numbers of person onboard generally.

\subsection{A problem in case that there is the maximum value of the number of fatalities}

All points which consist ALARP upper border should satisfy Principle A. However, if ALARP upper border is a straight line in double logarithmic graph, the point of maximum number of fatalities does not satisfy Principle A usually, that is contribution to PLL at maximum number of fatalities is larger than that at the number below maximum number. If $N$ denotes number of fatalities and $\mathrm{f}(N)$ denotes frequency of accidents whose number of fatalities, these accidents' contribution to PLL is a product of $\mathrm{N}$ and $\mathrm{f}(N)$.

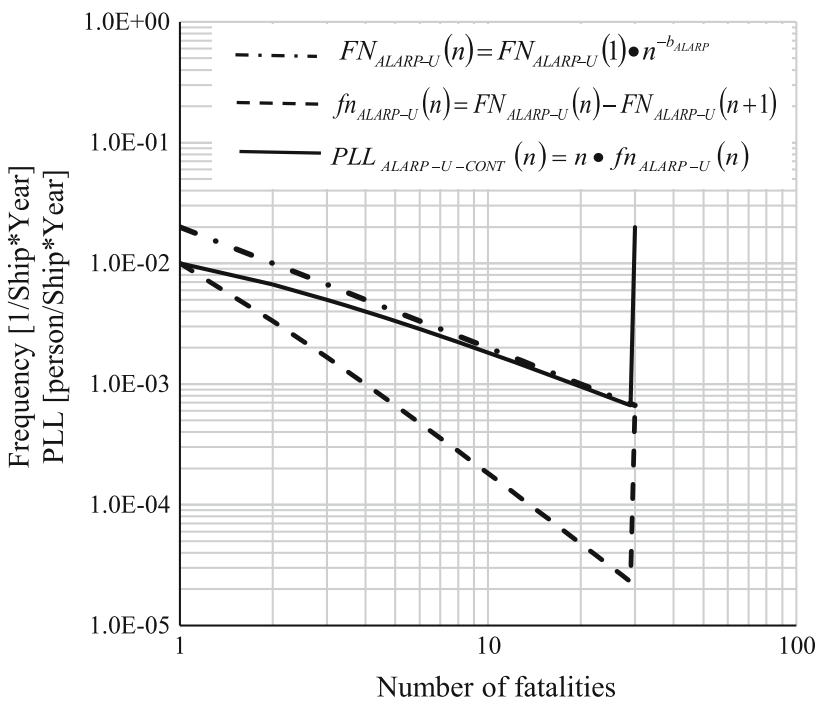

Fig. 6 An example where risk aversion is not realized at maximum number of fatalities $\left(b_{\mathrm{ALARP}}=1\right)$

Figure 6 shows an example of this phenomena. In Fig. 6 ALARP upper border whose slope is -1 is drawn as a dashed line, $\mathrm{fn}_{\text {ALARP-U }}(n)$ is drawn as a broken line and contribution to PLL of ALARP upper border denoted as PLL $_{\text {ALARP-U-CONT }}(n)$ is drawn as a solid line. It is obvious that PLL $\mathrm{ALARP}_{\mathrm{AL}-\mathrm{CONT}}\left(N_{\max }\right)$ is larger than PLL $\mathrm{ALARP}_{\mathrm{A}-\mathrm{U}}$ CONT $\left(N_{\max }-1\right)$.

In addition, the following consideration reveals a condition that enables ALARP upper border of straight line in double logarithmic graph satisfy Principle A.

The inequality in Eq. 20 is required for ALARP upper border to satisfy Principle $A$ at maximum number of fatalities. $\mathrm{fn}_{\mathrm{ALARP}-\mathrm{U}}\left(N_{\max }-1\right) \cdot\left(N_{\max }-1\right)>\mathrm{fn}_{\mathrm{ALARP}-\mathrm{U}}\left(N_{\max }\right) \cdot N_{\max }$

Here, considering next relation, the inequality in Eq. 21 must hold in order that the inequality in Eq. 20 holds. 
Table 4 Minimum of exponent(H) of ALARP upper border which is straight line in double logarithmic graph in order that it can satisfy principle A

\begin{tabular}{lllllll}
\hline Maximum number of fatality & 1 & 2 & 3 & 4 & 5 & 6 \\
Minimum of exponent $(\mathrm{H})$ & NA & $1.58 \mathrm{E}+00$ & $2.26 \mathrm{E}+00$ & $2.95 \mathrm{E}+00$ & $3.63 \mathrm{E}+00$ & $4.32 \mathrm{E}+00$ \\
\hline Maximum number of fatality & 10 & 20 & 30 & 40 & 50 & 100 \\
Minimum of exponent $(\mathrm{H})$ & $7.09 \mathrm{E}+00$ & $1.40 \mathrm{E}+01$ & $2.10 \mathrm{E}+01$ & $2.79 \mathrm{E}+01$ & $3.48 \mathrm{E}+01$ & $6.95 \mathrm{E}+01$ \\
\hline
\end{tabular}

$$
\begin{aligned}
& \operatorname{fn}_{\text {ALARP-U }}\left(N_{\max }-1\right)= \mathrm{FN}_{\text {ALARP-U }}\left(N_{\max }-1\right) \\
&-\mathrm{FN}_{\text {ALARP-U }}\left(N_{\max }\right) \\
&= \mathrm{FN}_{\text {ALARP-U }}(1)\left(\left(N_{\max }-1\right)^{-b_{\text {ALARP-U }}}\right. \\
&\left.-\left(N_{\max }\right)^{-b_{\text {ALARP-U }}}\right) \mathrm{fn}_{\text {ALARP-U }}\left(N_{\max }\right) \\
&= \mathrm{FN}_{\text {ALARP-U }}\left(N_{\max }\right) \\
&= \mathrm{FN}_{\text {ALARP-U }}(1)\left(N_{\max }\right)^{-b_{\text {ALARP-U }}} \\
&\left(N_{\max }-1\right)\left(\left(N_{\max }-1\right)^{-b_{\text {ALARP-U}}}-\left(N_{\max }\right)^{-b_{\text {ALARP-U }}}\right) \\
&-N_{\max } \cdot\left(N_{\max }\right)^{-b_{\text {ALARP-U }}}>0
\end{aligned}
$$

From the inequality in Eq. 21 the inequality in Eq. 22 can be derived.

$b_{\text {ALARP-U }}>1-\frac{\ln \left(2-\frac{1}{N_{\max }}\right)}{\ln \left(1-\frac{1}{N_{\max }}\right)}$

The inequality in Eq. 22 shows a condition which the slope of ALARP upper border of straight line must satisfy. Table 4 shows the least value of $b_{\text {ALARP-U }}$ which satisfies inequality (21) to some maximum number of fatalities. The table indicates that the least $b_{\text {ALARP-U }}$ is 14.0 where maximum number of fatality is 20 which is as same as crew number of usual cargo carrying ship. This means that usual value of a slope of ALARP upper border, such as 1.0 or 2.0 cannot satisfy Principle A at maximum number of fatalities.

\subsection{ALARP upper border which allows more fatal accidents than less fatal accidents}

In addition to the above-mentioned problems ALARP upper border of straight line has a problem that allowance ratio between ALARP upper borders and existing FN diagrams at a severer accident is larger than that at a smaller accident. Here it should be noted that risk allowance is the matter the relevant society should determine. However, it is rational that more fatalities at an accident should be less allowable. In addition ALARP upper border of straight line has further problem that allowance ratio at few fatalities is much larger than that at large fatalities.

A figurative example which shows those problems is shown in Fig. 7 which includes FN diagram of general cargo ships during 17-year period from 1995 to 2011 and imaginary

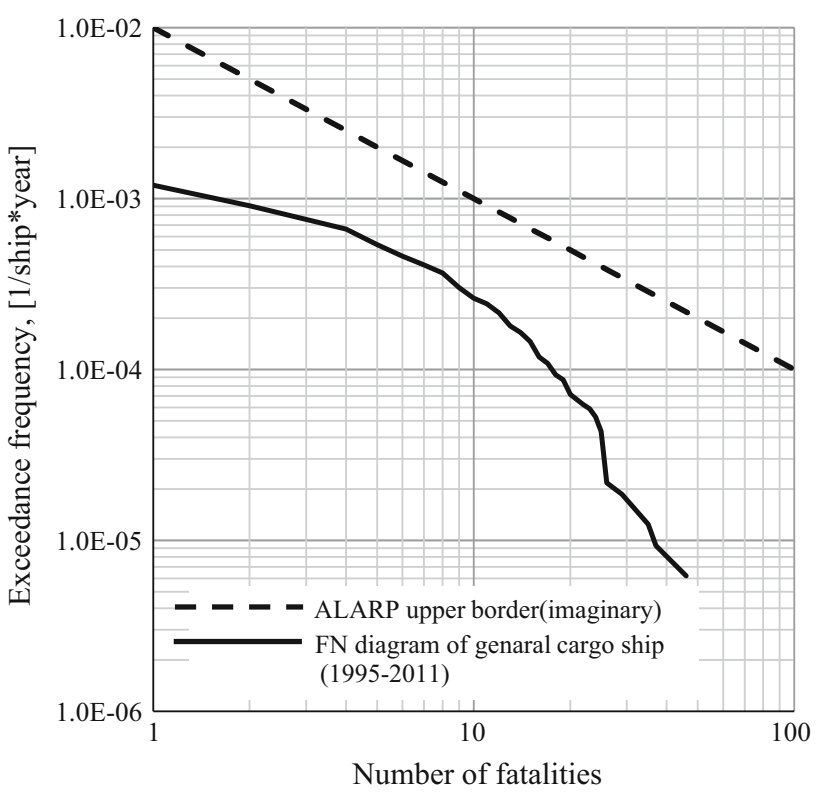

Fig. 7 FN diagram of general cargo ship and straight ALARP upper border

Table 5 Allowance ratio between the FN diagram and the straight ALARP upper border

\begin{tabular}{llllll}
\hline No. of fatality & 1 & 5 & 10 & 20 & 46 \\
\hline Allowance ratio & 8.4 & 3.7 & 3.8 & 7.0 & 35.0 \\
\hline
\end{tabular}

ALARP upper border of straight line slope of which is -1 . Table 5 shows allowance ratios between the ALARP border and the FN diagram at some numbers of fatalities. Figure 6 and Table 5 show that the domain of numbers of fatalities between 5 and 10 shows the least allowance ratio. Figure 7 and Table 4 also show that allowance ratio at maximum fatalities is 10 times larger than that at the domain of numbers of fatalities between 5 and 10. Moreover, it is expected that the ratio becomes the larger as the ALARP upper border of straight line gets nearer to the FN diagram.

\section{New method for setting ALARP upper border on FN diagram}

In this chapter two new methods for setting ALARP upper border to FN diagrams, which can resolve problems shown 
in the former chapter are introduced. The new ALARP upper borders set by those new methods are set to approximated FN diagram. ALARP lower border can be set by multiplying ALARP upper border by the ratio between ALARP upper and lower border of individual risk.

\subsection{Methods}

\subsubsection{Setting ALARP upper border to be parallel to approximated FN diagram (ALARP upper border of Type I)}

This section shows a method for setting ALARP upper borders to be parallel to an approximated FN diagram using Eq. 23. The method is to set ALARP upper border by multiplying a value of approximated FN diagram so that summation of ALARP upper border can become the multiplication of ALARP upper border of individual risk

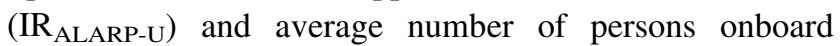
$\left(N_{\text {obd }}\right)$. This type of ALARP upper/lower border is called Type I in this article.

$$
F N_{A L A R P-U}(n)=\frac{I R_{A L A R P-U} \cdot N_{o b d}}{\sum_{i=1}^{N_{\max }} F N_{\text {aprx }}(i)} F N_{\text {aprx }}(n)
$$

\subsubsection{Setting ALARP upper border in order that allowance ratio between ALARP upper border and approximated FN diagram becomes smaller as number of fatalities becomes larger (ALARP upper border of Type II)}

In order that allowance ratio between ALARP upper borders and approximated FN diagrams becomes smaller as numbers of fatalities are getting larger, values of which can be expressed by Eq. 24, whose components are frequency of accidents and number of fatalities expressed by Eq. 23 .

$\mathrm{fn}_{\mathrm{ALARP}-\mathrm{U}}(n)=g(n) \mathrm{fn}_{\mathrm{aprx}}(n)$

$g(n)=\alpha\left(\frac{N_{\max }}{n}\right)^{\mathrm{y}}$

The procedure for obtaining $\alpha$ and $\mathrm{y}$ in Eq. 25 is as follows.

1. Predetermine $\alpha$ which is allowance ratio at maximum number of fatalities of approximated $\mathrm{FN}$ diagram.

2. Obtain y by solving Eq. 26 which means that PLL of ALARP upper border divided by average number of persons onboard equals to ALARP upper border of individual risk.

Newton-Raphson method can be applied to solve Eq. 26.
$\mathrm{IR}_{\mathrm{ALARP}-\mathrm{U}}=\frac{\sum_{n=1}^{N_{\max }} \alpha\left(\frac{N_{\max }}{n}\right)^{y} \cdot n \cdot \mathrm{fn}_{\mathrm{aprx}}(n)}{N_{\text {obd }}}$

This type of ALARP upper/lower border is called Type II in this article.

4.2 ALARP regions of major ship types by application of new ALARP upper border setting methods

Type I and Type II of ALARP upper and lower borders of major ship types which are set by application of the methods explained above are shown in Fig. 8 with FN diagrams made from casualty data and approximated FN diagrams. For keeping correspondence with Figs. 1 and 4 symbol $i$ is not used in Fig. 7. In ALARP upper/lower border of Type II $\alpha$ is set to 2 . When setting these ALARP borders, following to FSA guidelines ALARP upper border of individual risk to cargo carrying ships was set to $10^{-3}$ $[1 /($ ship $\times$ year $)]$ and that to passenger ships was set to $10^{-4}[1 /($ ship $\times$ year $)]$. ALARP lower border of individual risk to both ship types was set to $10^{-6}$ [1/( hip $\times$ year $\left.)\right]$. Average number onboard of every ship type was obtained by averaging number of crew and passengers which were recorded in IHSF ship database and in service in the period from 1995 to 2011.

Figure 8 shows that all ship types except RORO passenger ship are within ALARP region of both type. It also shows that those ship types' ALARP upper borders of both types do not allow allowance ratio of accidents with more fatalities to be larger than that of less fatalities. For those ALARP upper borders are obtained in order that summation of them are equal to ALARP upper borders of individual risk divided by average number of persons onboard of corresponding ship types, those values must be the same. We also checked that those values are the same by calculation.

\section{Discussion}

\subsection{Goodness-of-fit test to approximation functions}

Goodness-of-fit test to approximation functions by MDPLDwUL was carried out. Table 6 shows the results. Goodness-of-fit test is to test whether theoretical probabilistic distribution express a distribution of observed data precisely based on the fact that a value obtained by Eq. 27 distributes following Chi-square distribution (on goodnessof-fit test, refer Jun Shao [15] for example).

$\chi^{2}=\sum_{j=1}^{K} \frac{\left(X_{j}-n \cdot p_{j}\right)^{2}}{n \cdot p_{j}}$ 
Fig. 8 Approximated FN diagrams by MDPLDwUL and corresponding ALARP borders

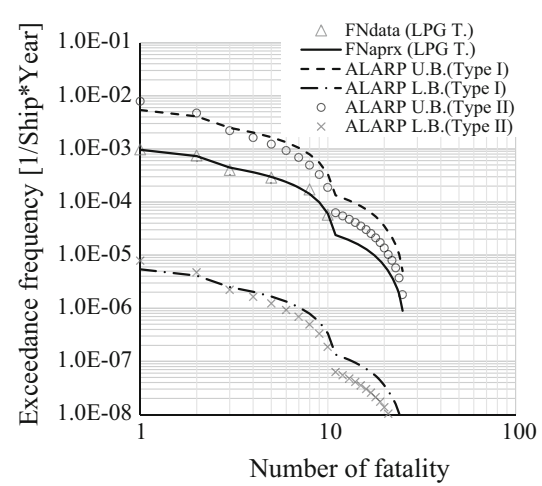

(a) LPG tanker

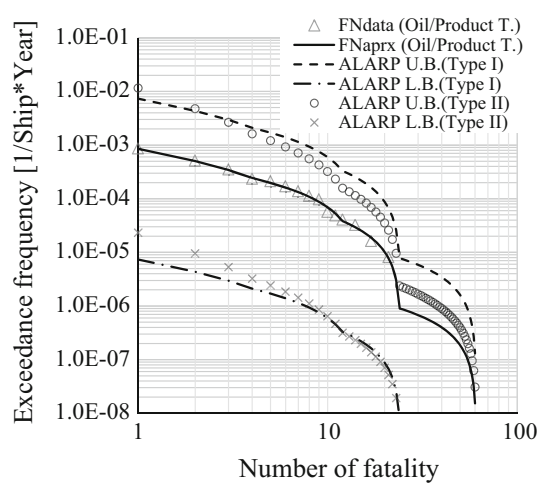

(c) Oil/Product tanker

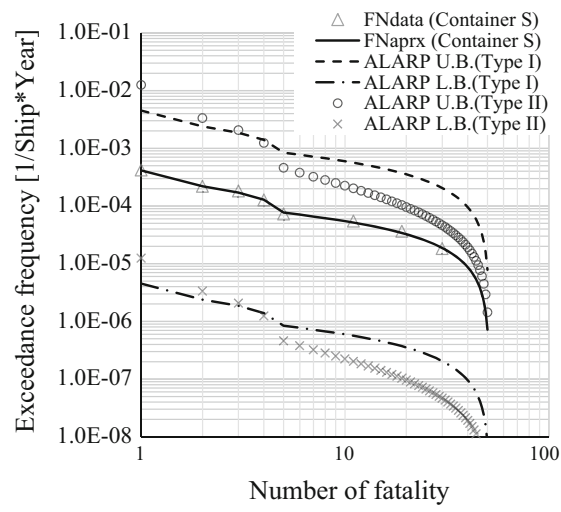

(e) General cargo ship

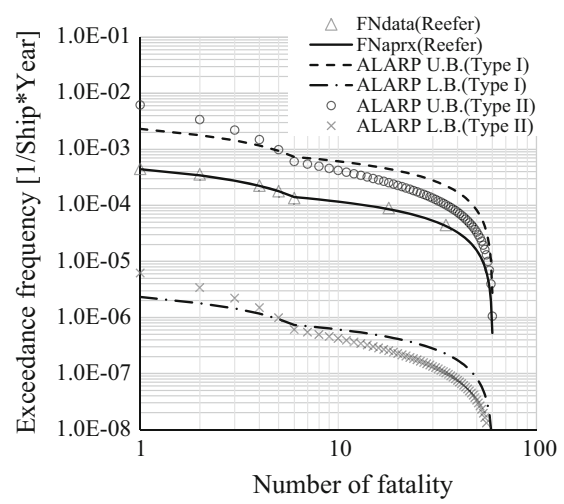

(g) Refrigerated cargo ship

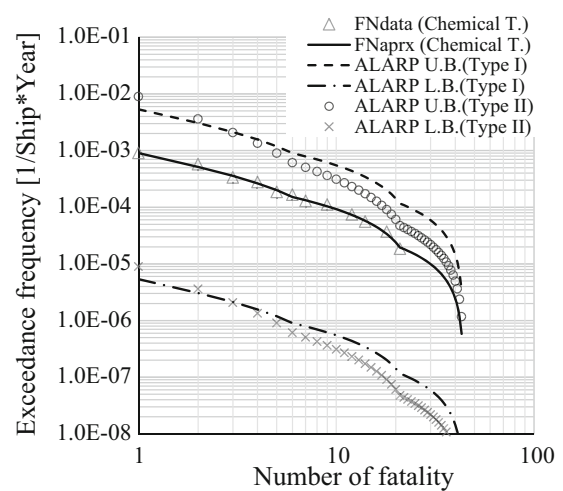

(b) Chemical tanker

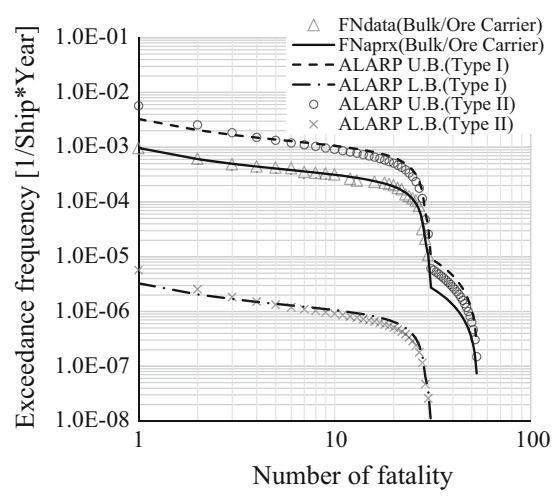

(d) Bulk/Ore carrier
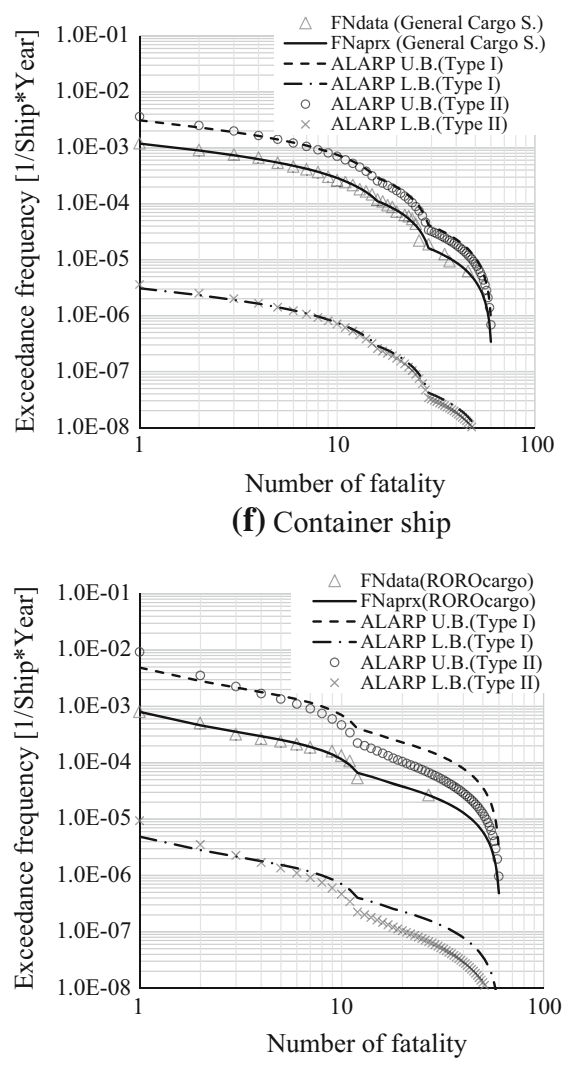

(h) RORO Cargo ship 
Fig. 8 continued

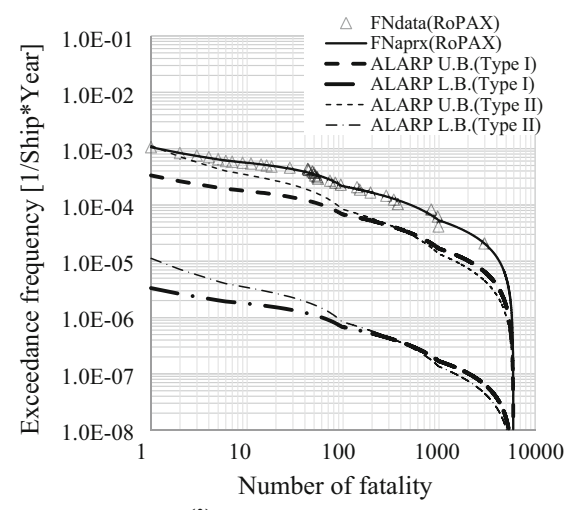

(i) RORO passenger ship

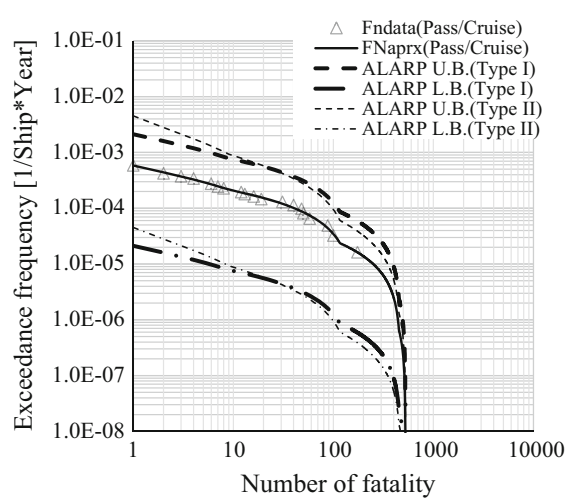

(j) Passenger/Cruise ship where $X_{j}$ denotes observed data $(j=1, \ldots, K), p_{j}$ denotes probability of $j$ th category of theoretical probabilistic distribution, $n$ denotes number of observed data $\left(n=\sum_{j=1}^{K} X_{j}\right)$ and $K$ denotes number of categories which should be set as $n \times p_{j}$ is over 5 .

Results of the test with $5 \%$ significance level reveal that the null hypothesis that empirically approximated probabilistic distribution by MDPLDwUL well expresses the distribution from casualty data cannot be rejected at every ship type. Therefore, it can be said that the approximated FN diagrams are appropriate as those of major ship types considered here.

\subsection{Relation between individual risk and ALARP region}

Table 7 is a table of risk profiles of the major ship types, which shows frequency of fatal accidents, PLL, individual risk with relating values [16]. It is observed that general cargo ship has the largest individual risk of all cargo carrying ship types and bulk/ore carrier has the second largest. In correspondence to this Fig. 8 shows that ALARP upper border of general cargo ships is the closest to its FN diagram, and that of bulk/ore carrier is the second closed to its FN diagram of all cargo carrying ship types. In Table 7 it is observed that individual risk of RORO passenger ships is over twice as large as ALARP upper border of individual risk of passenger ships, i.e., $10^{-4}$. In correspondence to this Fig. 8 shows that FN diagram of RORO passenger ships is beyond its ALARP upper border. Individual risk of container ship is the smallest except LNG tanker of all cargo carrying ship types.

In correspondence to this, distance between ALARP upper border and FN diagram of container ships is the longest of all cargo carrying ship types. General cargo ships' ALARP upper border of Type I and that of Type II are very close. This is because allowance ratio of ALARP upper border of type I to the FN diagram is 2.6 which is very close to 2.0. Figure 8 indicates that Type II ALARP upper border is suitable to restrict accidents of more fatalities more severely.

\subsection{Risk aversion of ALARP upper border}

As ALARP upper border of Type I has the same characteristics of the corresponding FN diagram if FN diagram of some ship type does not satisfy Principle A, a debate will
Table 6 Results of goodnessof-fit test of the approximation functions for FN diagrams of major ship types

\begin{tabular}{llll}
\hline Ship type & $\chi^{2}$ & $\chi_{K-1}^{2}(\alpha=0.05)$ & DOF $(\mathrm{K}-1)$ \\
\hline LPG tanker & $1.77 \mathrm{E}-01$ & $3.84 \mathrm{E}+00$ & 1 \\
Chemical tanker & $3.65 \mathrm{E}+00$ & $9.49 \mathrm{E}+00$ & 4 \\
Oil tanker & $1.82 \mathrm{E}+00$ & $1.26 \mathrm{E}+01$ & 6 \\
Bulk carrier & $8.94 \mathrm{E}+00$ & $1.69 \mathrm{E}+01$ & 9 \\
General cargo carrier & $2.91 \mathrm{E}+01$ & $3.14 \mathrm{E}+01$ & 20 \\
Container carrier & $3.05 \mathrm{E}-03$ & $5.99 \mathrm{E}+00$ & 2 \\
Refrigerated cargo carrier & $7.56 \mathrm{E}-04$ & $3.84 \mathrm{E}+00$ & 1 \\
RORO cargo carrier & $2.14 \mathrm{E}+00$ & $7.81 \mathrm{E}+00$ & 3 \\
RORO passenger ship & $2.27 \mathrm{E}+00$ & $1.41 \mathrm{E}+01$ & 7 \\
Passenger/cruise ship & $1.20 \mathrm{E}+00$ & $9.49 \mathrm{E}+00$ & 4
\end{tabular}


Table 7 Risk profiles of major ship types during a period from 1995 to 2011 [16]

\begin{tabular}{|c|c|c|c|c|c|c|c|c|}
\hline Ship type & $\begin{array}{l}\text { Exposure } \\
(\text { ship } \times \text { year) }\end{array}$ & $\begin{array}{l}\text { Number } \\
\text { of fatal } \\
\text { accidents }\end{array}$ & $\begin{array}{l}\text { Number } \\
\text { of fatalities }\end{array}$ & $\begin{array}{l}\text { Average } \\
\text { number } \\
\text { of crew }\end{array}$ & $\begin{array}{l}\text { Average } \\
\text { number } \\
\text { of fatalities }\end{array}$ & $\begin{array}{l}\text { Frequency } \\
\text { of fatal } \\
\text { accidents } \\
(1 / \text { ship } \times \text { year })\end{array}$ & $\begin{array}{l}\text { PLL } \\
\text { (person/ } \\
\text { ship } \times \text { year) }\end{array}$ & $\begin{array}{l}\text { Individual } \\
\text { risk } \\
(1 / \text { ship } \times \text { year })\end{array}$ \\
\hline LNG tanker & 3,144 & 2 & 7 & 37.0 & 3.5 & $6.36 \mathrm{E}-04$ & $2.23 \mathrm{E}-03$ & $6.01 \mathrm{E}-05$ \\
\hline LPG tanker & 17,599 & 17 & 58 & 20.6 & 3.4 & $9.66 \mathrm{E}-04$ & $3.30 \mathrm{E}-03$ & $1.60 \mathrm{E}-04$ \\
\hline Chemical tanker & 54,411 & 49 & 171 & 21.1 & 3.5 & $9.01 \mathrm{E}-04$ & $3.14 \mathrm{E}-03$ & $1.49 \mathrm{E}-04$ \\
\hline Oil/product tanker & 124,089 & 106 & 367 & 25.8 & 3.5 & $8.54 \mathrm{E}-04$ & $2.96 \mathrm{E}-03$ & $1.15 \mathrm{E}-04$ \\
\hline Bulk/ore carrier & 94,246 & 91 & 755 & 27.4 & 8.3 & $9.66 \mathrm{E}-04$ & $8.01 \mathrm{E}-03$ & $2.92 \mathrm{E}-04$ \\
\hline General cargo ship & 322,126 & 385 & 2,507 & 20.5 & 6.5 & $1.20 \mathrm{E}-03$ & $7.78 \mathrm{E}-03$ & $3.79 \mathrm{E}-04$ \\
\hline Container ship & 55,392 & 23 & 101 & 23.5 & 4.4 & $4.15 \mathrm{E}-04$ & $1.82 \mathrm{E}-03$ & $7.77 \mathrm{E}-05$ \\
\hline Refrigerated cargo ship & 22,556 & 10 & 76 & 23.1 & 7.6 & $4.43 \mathrm{E}-04$ & $3.37 \mathrm{E}-03$ & $1.46 \mathrm{E}-04$ \\
\hline RORO cargo ship & 37,303 & 30 & 133 & 25.1 & 4.4 & $8.04 \mathrm{E}-04$ & $3.57 \mathrm{E}-03$ & $1.42 \mathrm{E}-04$ \\
\hline $\begin{array}{l}\text { Passenger general cargo } \\
\text { ship }\end{array}$ & 7,256 & 5 & 18 & 366.8 & 3.6 & $6.89 \mathrm{E}-04$ & $2.48 \mathrm{E}-03$ & $6.76 \mathrm{E}-06$ \\
\hline RORO passenger ship & 48,221 & 51 & 8,034 & 713.3 & 157.5 & $1.06 \mathrm{E}-03$ & $1.67 \mathrm{E}-01$ & $2.34 \mathrm{E}-04$ \\
\hline Passenger/cruise ship & 61,755 & 36 & 722 & 534.2 & 20.1 & $5.83 \mathrm{E}-04$ & $1.17 \mathrm{E}-02$ & $2.19 \mathrm{E}-05$ \\
\hline
\end{tabular}

be caused on whether ALARP upper border of Type I is appropriate as ALARP upper border.

However, ALARP upper border of Type II is considered to resolve this problem even if FN diagram of some ship type does not satisfy Principle A. This reason is that as fn $(n)$ is proportional to an exponent of $n$, Eq. 24 is transformed to Eq. 28 which indicates that exponent $(\mathrm{H}) \mathrm{s}$ of DPLDwUL of elemental sub-groups become larger.

$$
\begin{array}{r}
\operatorname{fn}_{\text {ALARP-U }}(n)=\alpha\left(\frac{N_{\max }}{n}\right)^{y} C \cdot n^{-b_{\text {ALARP-U }}} \\
=\alpha \cdot C \cdot\left(N_{\max }\right)^{y} n^{-\left(y+b_{\text {ALARP-U }}\right)}
\end{array}
$$

Therefore, if absolute values of exponent $(\mathrm{H}) \mathrm{s}$ of all DPLDwUL of all sub-groups become over 1.0, ALARP upper border of Type II satisfy Principle A, that is, risk averseness. Table 8 shows exponent(H)s of DPLDwUL of elemental sub-groups of ALARP upper border of Type II in case that $\alpha=1$ and 2 .

Table 8 shows that exponent (H)s of DPLDwUL of elemental sub-groups of ALARP upper border of Type II are over 1.0 except some ship types. Therefore, ALARP upper border of Type II can be used in case that ALARP upper border cannot satisfy Principle A.

\subsection{A proposal of new safety assessment method using approximate function of FN diagram by MDPLDwUL}

It is recognized that FN diagram of all major ship types can be approximated by MDPLDwUL with high accuracy to the extent that the approximated FN diagram can pass goodness-of-fit test. Here the number of sub-groups, exponent $(\mathrm{H}) \mathrm{s}$ of DPLDwUL and maximum number of fatalities of sub-groups were obtained by optimization. On the other hand there is the other method for determining parameters of MDPLDwUL. The method is that firstly divide ships of a ship type into some sub-groups by a certain criteria such as gross tonnage or a capacity with determining ratios and maximum numbers of fatalities, after that exponent (H)s of DPLDwULs of those subgroups are obtained by optimization. SDC 1/INF.7 [17] dealt with this method.

Following consideration is a proposal of new safety analysis method which uses FN diagrams approximated by MDPLDwUL assuming that division of sub-groups in a ship type proposed in this article is regarded to be rational.

As mentioned above, Table 8 shows that ship types whose sub-groups' DPLDwULs are all above 1.0 are only chemical and oil/product tankers. Therefore, these two ship types have satisfied Principle A during a period from 1995 to 2011. Bulk/ore carrier has three sub-groups whose number of fatalities are comparable. An exponent ( $b_{\text {ALARP-U }}$ ) of one of them is below zero. This means that accidents with more fatalities occur more easily than those with less fatalities. If the casualty database is carefully investigated, one can find such ship groups. It would be rational to consider that those sub-groups have priorities in considering risk control options (RCOs). Multiplication of a number of fatalities and the corresponding frequency of accidents produces contribution to PLL of the accidents. Figure 9 shows contribution of accidents to PLL to every ship type with each approximated FN diagram.

It can be found from Fig. 9 that contributions to PLL of chemical tanker, oil/product tankers and passenger/ 


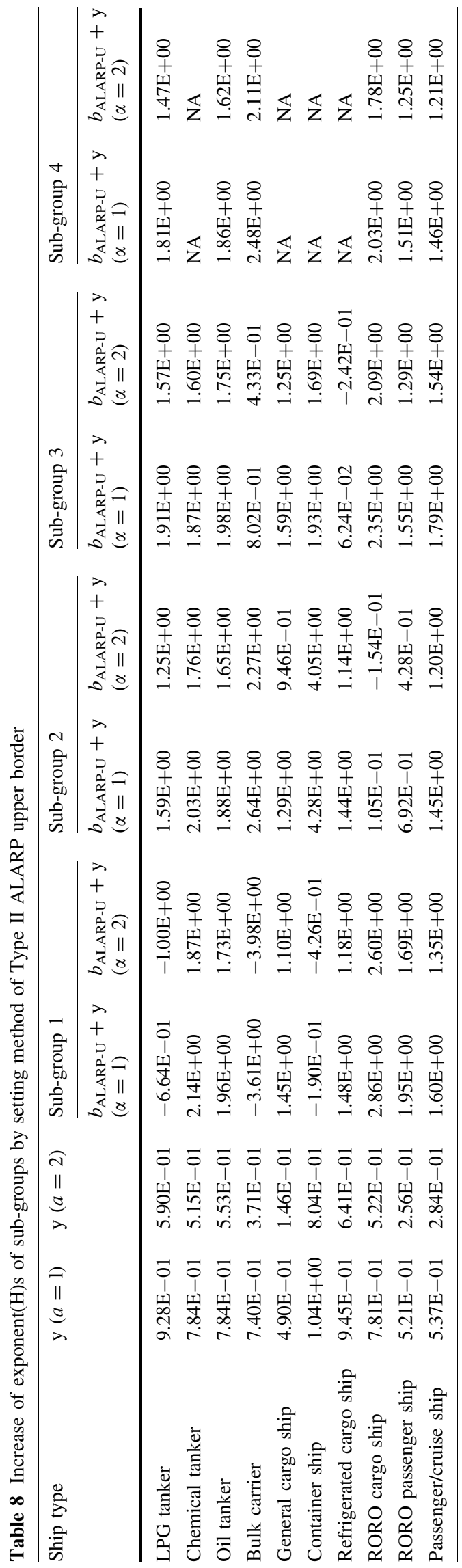

cruise ship are monotonically decreasing functions. This means these ship types exactly satisfy Principle A and show risk averse as a whole. Bulk/ore carrier shows the tendency that the contribution of accidents to PLL gets smaller as $\mathrm{n}$ gets larger until 8 , but it is rapidly increasing until 30 fatalities above 8 . The ship types that show a similar tendency as the bulk/ore carrier are container ship and RORO cargo ship. It can be said that these ship types are the types that there are accidents where comparatively many people die. However, as those ship types are in ALARP region cost-effective RCO should be continuously considered, especially RCOs which are thought to be effective for reducing contribution to PLL by accidents where comparatively many people would die is considered with high priority, after investigation the reason why many people died. Generally speaking peak of contribution to PLL should be resolved with high priority. The reason why there exist peaks of PLL is because there are sub-groups which cannot satisfy Principle A. Therefore, FN diagram's approximation method by MDPLDwUL is thought to be so useful to specify the DPLDwUL of such risky sub-groups which does not satisfy Principle A. However, the method to identify the sub-groups from IHSF casualty database should be considered in the future.

Figure 9 shows that the FN diagram of RORO passenger ships locates over its ALARP upper border. This directly means that it is urgent matter to reduce the fatality risk of RORO passenger ships by introducing some safety measures. However, Table 2 shows that number of sub-groups which does not satisfy Principle A is one and that $N_{\max }$ of the sub-group is 96 . In this connection Fig. 9j also shows that contribution to PLL is growing from 7 fatalities to 96 fatalities. It is thought that a sub-group of RORO passenger ships whose number of fatalities could be less than or equal to 96 is a risky group. As the number of fatalities is less than the number of persons onboard, this may mean that number onboard of such risky group may be ranging from dozens to hundreds. It is well known that relatively small RORO passenger ships are in service in sea areas around Philippines and Indonesia as means of transportation which connects islands. In addition, it is also known that many fatal accidents of such ships have happened in those sea areas historically. So there may be a possibility that the relatively small RORO passenger ships is the risky subgroup.

Table 2 and Fig. 9j show that sub-groups $N_{\max }$ of which are 993 and 5927 have exponent(H)s of DPLDwUL which are around 1.0. This means that these sub-groups almost satisfy Principle A. Therefore, it can be said that large RORO passenger ships whose number of persons onboard is more than 1000 are relatively safe. 
Fig. 9 Contribution of every number of fatalities to PLL derived approximated FN diagrams

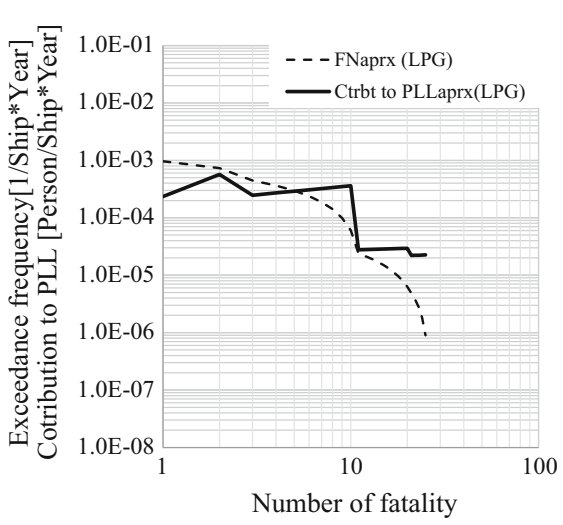

(a) LPG tanker

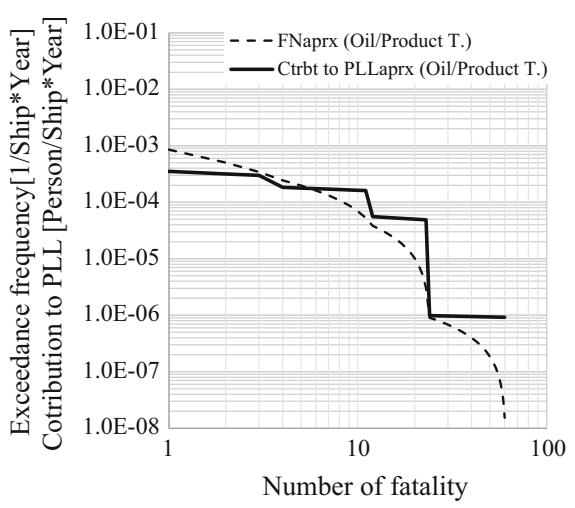

(c) Oil/Product tanker

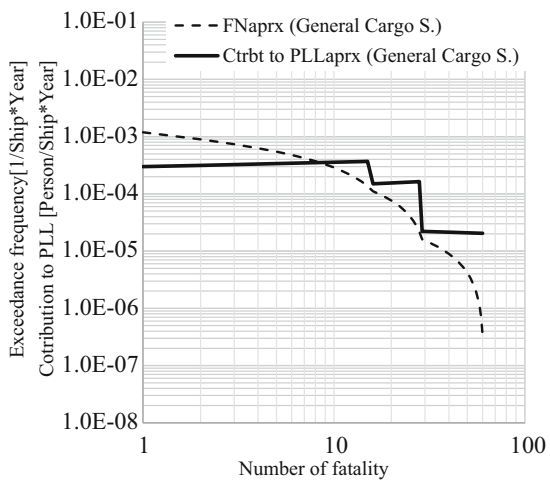

(e) General cargo ship

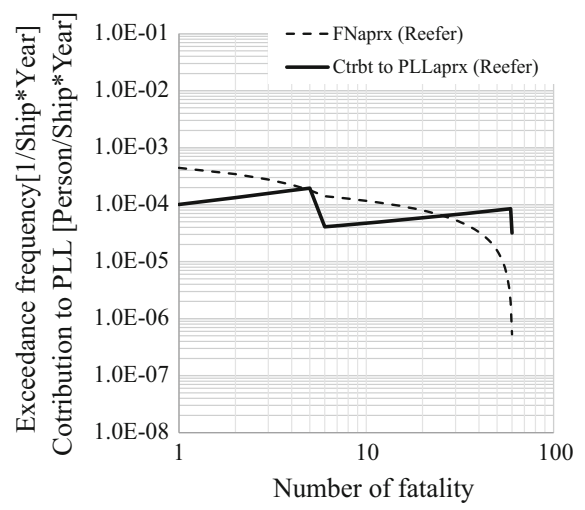

(g) Refrigerated cargo ship

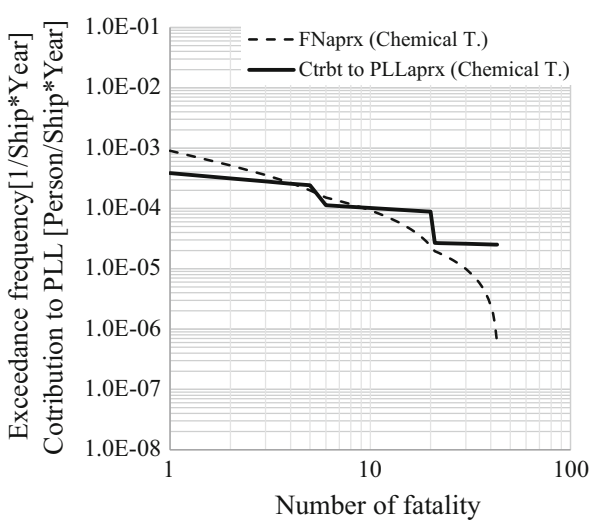

(b) Chemical tanker

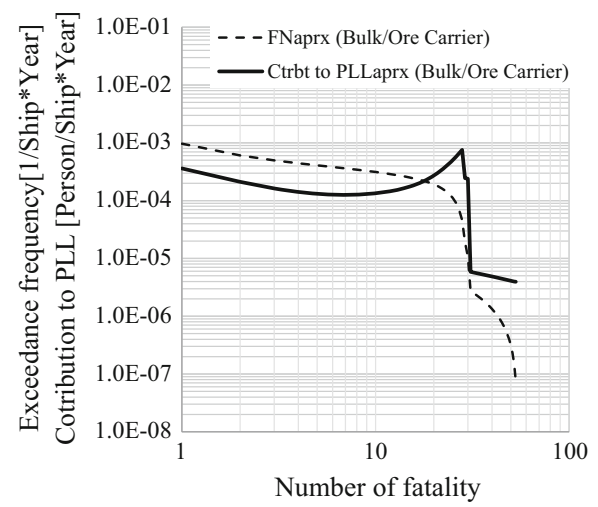

(d) Bulk/Ore carrier

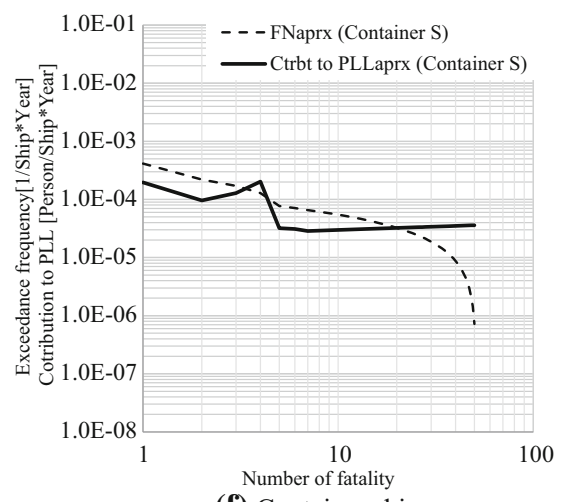

(f) Container ship

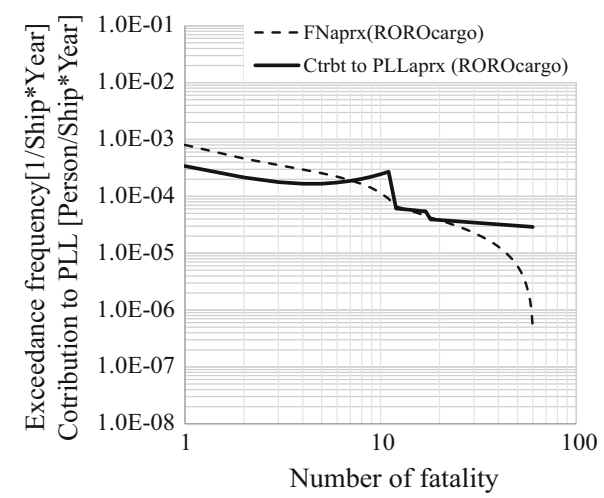

(h) RORO cargo ship 
Fig. 9 continued

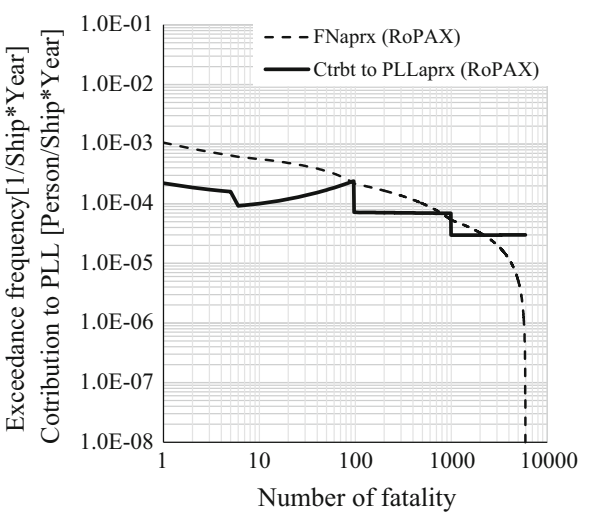

(i) RORO passenger ship

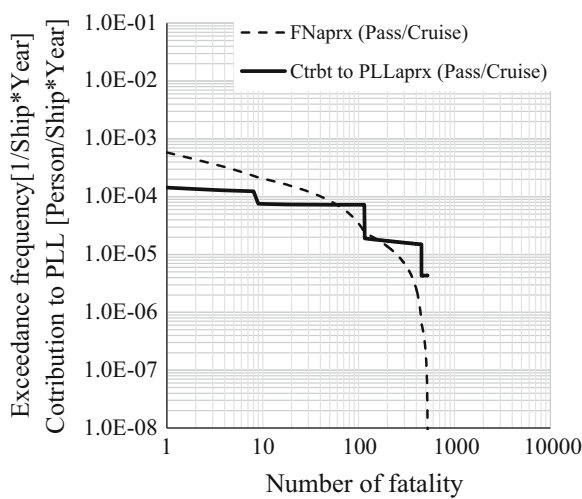

(j) Passenger/Cruise ship

\subsection{Utilization of approximated FN diagrams to risk-} based design

For maritime field has a lot of accident record, meaningful FN diagrams of major ship types can be made by those accident records. Furthermore, using such FN diagrams approximation of the diagrams by MDPLDwUL is possible as is done here. As the Sect. 5.1 shows, the approximated FN diagrams express existing risk profiles of those ship types precisely to the extent that it can pass the goodnessof-fit test. Therefore, the approximated FN diagrams for the targeted ship can be used in risk-based design of the ship as a default risk profiles of the ship. Furthermore, when some RCOs are considered, risk reduction by introducing the RCOs can be estimated by changing parameters of MDPLDwUL based on rational assumptions and by calculating difference between modified FN diagram and original it to every RCO.

\subsection{Updating of approximated FN diagrams}

It should be noted that the approximated FN diagrams obtained in the above are specific for the period from 1995 to 2011. Therefore, it is important for considering recent risk of ships to update approximated $\mathrm{FN}$ diagrams by adding accident records after 2012.

\section{Conclusion}

First of all the function called "Mixed Discrete Power Law Distribution with Upper Limit (abbreviated form: MDPLDwUL)" which can approximate all existing major ship types' FN diagrams with high accuracy is proposed. In addition, the method by which parameters of MDPLDwUL can be obtained using casualty data is developed. Then, it was validated using IHSF casualty and ship databases that MDPLDwUL can approximate
FN diagrams made from the casualty and ship data with high accuracy to the extent that it can pass the goodnessof-fit test. This method can extrapolate FN diagrams made from casualty data to the area of severer accidents with more fatalities, which have not been occurred yet, rationally. The approximated FN diagrams made here can be used as FN diagrams of existing major ship types, and they will be used in rule-making process or risk-based design effectively.

Secondly, two methods for setting ALARP upper borders are proposed and applied to setting ALARP upper borders of existing major ship types in order to resolve two kinds of inconsistency, i.e., inconsistency of ALARP upper border between in FN diagram and that in PLL, and inconsistency arisen from the usage of straight line as ALARP upper boarder in FN diagram. The first method called Type $\mathrm{I}$ is to move approximated FN diagram in parallel upward to the position where the corresponding individual risk of the ALARP upper border of the FN diagram equals to the ALARP upper border of individual risk. It can resolve a discrepancy between ALARP upper border of FN diagram, which is set based on economic importance of a considered ship type according to FSA guidelines, and ALARP upper border of individual risk, taking into account a fact that PLL is a sum of values of the vertical coordinates along whole FN diagram.

The second method called Type II is to set allowance ratio of more fatalities smaller than that of less fatalities keeping consistency of ALARP upper border between individual risk and $\mathrm{FN}$ diagram.

It can resolve inconsistency that has arisen from the usage of straight line, slope of which is -1 or -2 , as ALARP upper borders in double logarithmic graph. More specifically, it can resolve two kinds of problem. The one is the problem that Principle A, i.e., "the contribution of accidents with more fatalities to PLL of considered ship types should be smaller than the contribution of accidents with less fatalities to the PLL", cannot be satisfied at the 
maximum number of fatalities. The other is the problem that allowance ratios between ALARP upper borders and existing FN diagrams at the region of larger numbers of fatalities are much larger than those at the region of comparatively smaller numbers of fatalities.

Lastly, it can be concluded that both the method for approximating FN diagrams and the method for setting ALARP upper border proposed in this article are so general that they can be applied to risk analysis of the fields which have a lot of accident records like maritime field, such as aviation or automotive fields.

Open Access This article is distributed under the terms of the Creative Commons Attribution License which permits any use, distribution, and reproduction in any medium, provided the original author(s) and the source are credited.

\section{Appendix: Davidon-Fletcher-Powell method [18]}

Davidon-Fletcher-Powell method is one of optimization methods called conjugate gradient method. In this method, after assuming initial value of objective parameters, iterative computation is carried out to arriving at final combination of the parameters which maximize or minimize objective function by following process.

1. Obtain $d_{i}$ by an equation which is $d_{i}=-H_{i-1}$. $\nabla F\left(x^{(i)}\right)$.

2. After (1) obtain $\lambda_{i}$ which maximizes or minimizes $F\left(x^{(i)}+\lambda_{i}\right)$.

3. Obtain $x^{(i+1)}$ by an equation which is $x^{(i+1)}=x^{(i)}+\lambda_{i} d_{i}$.

4. Using $x^{(i+1)}$ and $x^{(i)}$ obtain $y_{i}$ by an equation which is $y_{i}=\nabla F\left(x^{(i+1)}\right)-\nabla F\left(x^{(i)}\right)$.

5. Obtain $H_{i}$ by an equation which is $H_{i}=H_{i-1}$ $+\lambda_{i} \frac{d_{i} d_{i}^{t}}{g_{i}^{t} H_{i-1} g_{i}}-\frac{H_{i-1} y_{i} y_{i}^{t} H_{i-1}}{y_{i}^{t} H_{i-1} y_{i}}$.

where $x$ : a vector consists of targeted parameters (here, $\left.x=\left(b_{1}, b_{2}, \cdots, b_{M}, r_{1}, r_{2}, \cdots, r_{M-1}\right)\right) \mathrm{F}(x)$ : objective function of $x$ to be maximized or minimized.

$g_{i}=\nabla F\left(x^{(i)}\right)$

$H_{0}=I$ (unit matrix)

$\frac{\partial F}{\partial b_{i}}=\frac{\partial}{\partial b_{i}}\left(\operatorname{Ln}\left(\sum_{i=1}^{M} r_{i} \frac{\sum_{j=n}^{N_{\max -\mathrm{i}}} j^{-b_{i}}}{\sum_{j=N_{\min -\mathrm{i}}-\mathrm{i}}^{N_{\max }} j^{-b_{i}}}\right)-\operatorname{Ln}\left(\mathrm{CCDF}_{\mathrm{data}}(n)\right)\right)^{2}$

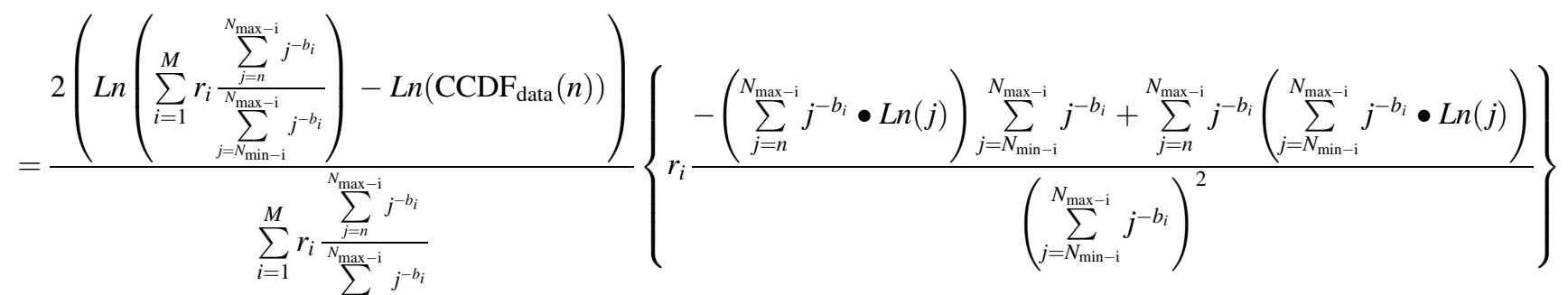

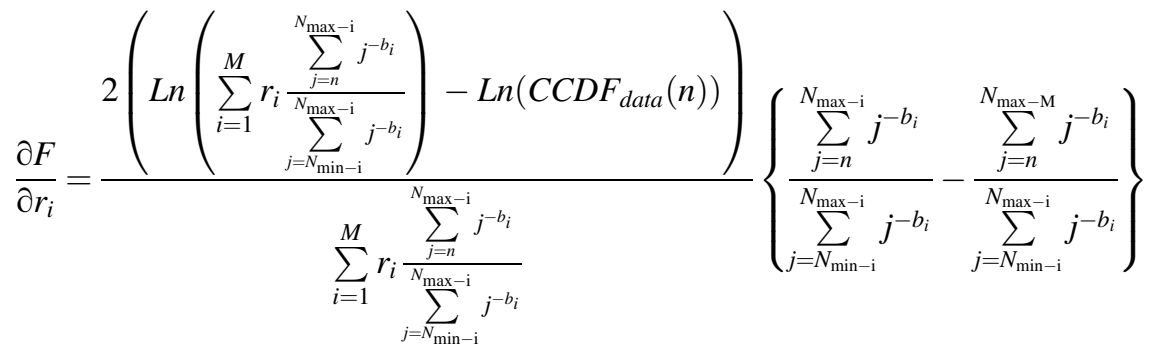




\section{References}

1. IMO (2013) Revised Guidelines for Formal Safety Assessment (FSA) for Use in the IMO Rule-Making Process, MSC-MEPC.2/ Circ

2. UK (2002) Bulk Carrier Safety-International Collaborative FSA Study-Final Report, MSC 76/5/5

3. Japan (2002) Bulk Carrier Safety-Report on FSA Study on Bulk Carrier Safety, MSC 75/5/2

4. Japan (2006) Preliminary FSA study on application of requirement of Inert Gas Systems to tankers of less than 20,000DWT, FP $51 / 10 / 1$

5. Japan (2006) Evaluation of cost-effectiveness of ECDIS in routes of cargo ships considering ENC coverage, NAV 52/6/2

6. Papanikolaou AD et al (2009) Risk-based design-methods, tools and applications. Springer, Berlin

7. Quinn DJ, Davies PA (2004) Development of an intermediate societal risk methodology-An investigation of FN curve representation, Research Report 283 of HSE, UK

8. IChemE (2009) An independent review of HSE methodology for assessing societal risk, HSE

9. Clauset A, Shalizi C, Newman MEJ (2009) Power-law distributions in empirical data. SIAM Rev 51:661-703
10. Virkar Y, Clauset A (2014) Power-law distributions in binned empirical data. Ann Appl Stat 8:89-119

11. Norway (2000) Formal Safety Assessment-Decision parameters including risk acceptance criteria, MSC 72/16

12. Train KE (2008) EM algorithms for nonparametric estimation of mixing distributions. J Choice Modelling 1(1):40-60

13. Jonkman SN, van Gelder PHAJM, Vrijling JK (2003) An overview of quantitative risk measures for loss of life and economic damage. J Hazard Mater A99:1-30

14. Vrijling JK et al (1995) A framework for risk evaluation. J Hazard Mater 43:245-261

15. Shao J (2003) Mathematical Statistics, 2nd edn. Springer Science+Business Media, LLC., New York, p 437

16. Kaneko F, Yuzui T (2014) Risk profiles of major ship types, proceedings of 24th ISOPE. Busan 4:579-586

17. Japan (2013) REVIEW OF THE DAMAGE STABILITY REGULATIONS FOR RO-RO PASSENGER SHIPS-information on the results of the study on survivability of passenger ships, SDC 1/INF.7

18. Kowalik J, Osborne MR (1968) Methods for Unconstrained Optimization Problems. American Elsevier Publishing Company, Inc., New York 